Article

\title{
Analysis of Heat Dissipation and Preheating Module for Vehicle Lithium Iron Phosphate Battery
}

\author{
Shuwen Zhou (D), Yuemin Zhao*(D) and Shangyuan Gao
}

Citation: Zhou, S.; Zhao, Y.; Gao, S. Analysis of Heat Dissipation and Preheating Module for Vehicle Lithium Iron Phosphate Battery. Energies 2021, 14, 6196. https:// doi.org/10.3390/en14196196

Academic Editor: Seung-Wan Song

Received: 9 August 2021

Accepted: 26 September 2021

Published: 28 September 2021

Publisher's Note: MDPI stays neutral with regard to jurisdictional claims in published maps and institutional affiliations.

Copyright: (C) 2021 by the authors Licensee MDPI, Basel, Switzerland. This article is an open access article distributed under the terms and conditions of the Creative Commons Attribution (CC BY) license (https:/ / creativecommons.org/licenses/by/ $4.0 /)$.
School of Mechanical Engineering and Automation, Northeastern University, Shenyang 110819, China; shwzhou@mail.neu.edu.cn (S.Z.); shangyuan2010@tom.com (S.G.)

* Correspondence: zhaoyuemin@tom.com

\begin{abstract}
The ambient temperature has a great influence on the discharge and charging performance of a lithium battery, which may cause thermal runaway of the battery pack in extreme cases. In terms of the poor cooling effect caused by only using the cooling bottom plate for liquid cooling and the fact that the battery pack needs to be preheated before it can be used normally, a new cooling structure design was carried out, and a variety of cooling schemes and preheating schemes were proposed for analysis and comparison. The Star $\mathrm{ccm}+$ simulation software was used to analyze and study their liquid cooling performance and preheating performance under different conditions. The best cooling scheme and preheating scheme were obtained by comparing the results of the simulation analysis. The simulation results show that the cooling performance of the cooling scheme using two vertical cooling plates and one cooling bottom plate is the best, and the preheating performance is best when the preheating liquid is used with a certain temperature flow through the preheating pipe of the battery pack for a period of time, and then the battery pack is discharged until the battery pack temperature reaches the working temperature range. The research results have reference value for the control of the ambient temperature of a vehicle lithium iron phosphate battery.
\end{abstract}

Keywords: heat-dissipating module; liquid cooling module; lithium iron phosphate battery; temperature rise; response surface analysis

\section{Introduction}

New energy vehicles powered by lithium batteries are gaining unprecedented attention and becoming more and more widely used [1]. However, the thermal runaway and damage to the immediate environment associated with this type of high-energy battery have become major safety concerns for electric vehicles [2,3].

Vehicle innovation is an inevitable trend of development under the multiple effects of energy shortage and technological innovation. At present, new energy vehicles are in line with this innovative development trend [4,5]. Its importance is self-evident because the power battery pack is a part of its power. However, a large amount of heat will be generated during the working process of the power battery pack. If the excess heat is not handled properly, it will cause overheating. The vehicle loses part of its efficiency and, in the worst-case scenario, the safety of passengers can be endangered. Therefore, dealing with this part of the heat is the main priority in research on the development of new energy vehicles [6,7]. Meanwhile, at low temperatures, there are restrictions when using lithium batteries: the viscosity of the internal electrolyte will increase, and the activity will decrease. Moreover, this will reduce the capacity of the lithium battery, so they cannot provide the best performance. At this time, thermal runaway or even safety accidents can occur due to the use of high current charging, so the preheating of the battery pack is also very important under low-temperature conditions.

The power battery is generally placed in the battery pack in a certain combination, and the battery pack has anti-collision, waterproof and anti-leakage properties [8]. The 
main cause of fire in most electric vehicles is thermal runaway caused by external impacts or improper control of the power battery [9]. For example, during spring and summer, electric vehicles are more likely to catch fire. This has caused changes in the performance of the power battery and led to abnormal chemical properties because of environmental factors such as long-term high temperatures or rain during these two seasons [10]. There are loopholes in the battery thermal management system, which causes the heat generated during driving to accumulate, and the temperature may be too high to cause a fire; during a collision with a foreign object, the original battery pack structure is deformed, resulting in leakage of the coolant or tilting of the battery, leading to fire [11]. These existing problems require the power battery pack to be designed to have good sealing performance in order to avoid external liquid infiltration into the battery pack to cause short circuits and avoid electrolyte contact with external oxygen; high hardness performance is also needed in order to avoid external collisions or sharp objects that cause the shell to rupture, as well as good heat insulation performance to avoid affecting the internal temperature of the battery pack when the ambient temperature is too high [12].

Recently, in order to prolong the cycle life and maximize the capability of power cells, a number of battery thermal management (BTM) strategies with external cooling (or heating), such as active cooling with air or liquid and passive cooling with a phase change material or heat pipe, have been developed [13-15]. With the recent increase in the battery pack energy density and load, air is unsuitable for use as cooling media in BTMS because of the poor heat capacity and low thermal conductivity [16]. PCM absorbs heat through its own material properties to reduce the temperature of the battery. However, depletion of the available latent heat under extreme conditions-such as high heat density during a high-current charge or discharge, or high ambient temperature-may cause failures of the thermal management systems [17]. Even under mild conditions (ambient temperature $<30{ }^{\circ} \mathrm{C}$ and discharge rate $<2{ }^{\circ} \mathrm{C}$ ), a lack of external cooling may also lead to thermal management system failures [18]. Moreover, liquid-based systems have high heat transfer efficiency with the function of cooling or heating [19]. Therefore, all the research in this paper is based on the liquid cooling of BTMS.

To date, scholars have designed many schemes for heat dissipation in vehicle lithium batteries. However, most of their heat dissipation schemes use a single cooling base plate to dissipate heat, and the preheating model is complicated. There is still little in-depth research on preheating strategies in low-temperature environments. Therefore, the cooling structure presented in this paper adds a vertical cooling plate so that the cooling pipes are buried in the vertical cooling plate and the cooling bottom plate. The structure increases the cooling effect, and, on this basis, the cooling scheme with the best cooling performance is selected. In addition, a new preheating strategy is proposed for low-temperature environmental conditions, and the preheating pipeline is improved, which can effectively shorten the time to reach the battery temperature required for normal operation of the battery pack. At the same time, because the preheating scheme structure is the same as the cooling scheme structure, it can not only ensure that the battery pack can adapt to different working conditions but also saves costs to a certain extent.

In the second section of this paper, the establishment of the simulation model of a single battery module in Star ccm + and the setting of related parameters are carried out, and then the simulation analysis is carried out under different environments and different discharge rate conditions. After this, in the third section, the design of the new cooling scheme based on liquid cooling is simulated and analyzed, and the conditions of discharge rate, coolant flow rate, number of cooling channels and number of cooling plates are changed to select the best cooling scheme; we then carry out response surface optimization analysis to further optimize the scheme.

\section{Establishment of Single Battery Module Model}

In this paper, a single battery module composed of prismatic lithium iron phosphate batteries is used for research and discussion. The size of the square lithium iron phosphate 
battery is $17 \times 011 \times 019 \mathrm{~mm}^{3}, 18$ square lithium iron phosphate composed of a single battery module. The space between individual cells is $1.5 \mathrm{~mm}$. The schematic diagram is shown in Figure 1.

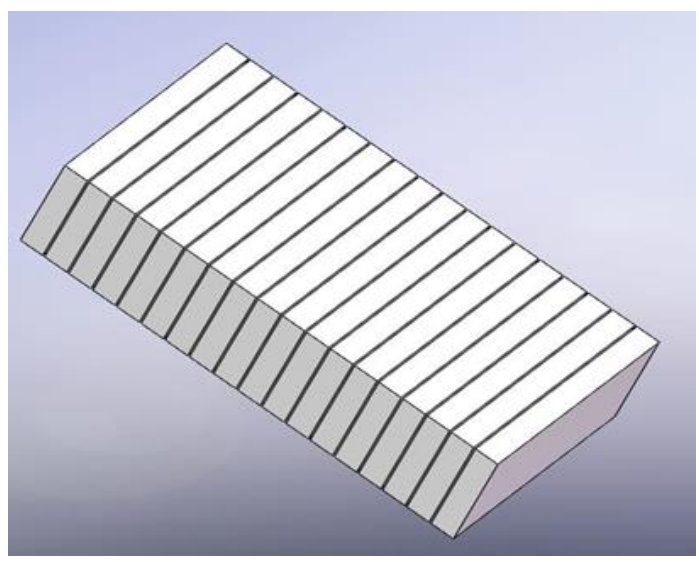

Figure 1. Single battery module model.

This paper selects prismatic lithium iron phosphate batteries for research, and the reasons are as follows:

(1) The normal working temperature range of lithium iron phosphate batteries is obviously larger than the normal working temperature range of lead-acid batteries and nickel-metal hydride batteries.

It is more flexible and can adapt to a wide range of actual working conditions [20].

(2) Lithium iron phosphate batteries have a larger number of charge and discharge cycles and a longer cycle life that is much higher than that of lead-acid batteries and nickel-hydrogen batteries and the service life of lithium iron phosphate batteries [21].

(3) A single lithium iron phosphate battery has a higher working voltage, which means that the use of a lithium iron phosphate battery can reduce the number of batteries in the vehicle power battery pack to a certain extent [22].

(4) A Ni-MH battery has a high self-discharge rate. If the battery is not used for a long time, a large amount of battery energy will be lost, which will affect the service life and performance of the battery [23]. In comparison, it is less than $5 \%$ of the self-discharge rate of lithium iron phosphate batteries. This means that the lithium iron phosphate battery can save energy for a long time. Furthermore, when it is not used for a long time, it will not lose a great deal of battery energy, increasing the additional costs [24].

(5) A lithium iron phosphate battery has no memory effect $[25,26]$.

\subsection{Simplification of Simulation Model Conditions}

In actual production and real-world application, in order to obtain the exact value of the heat-generating accurate battery total heat $Q$, the charge and discharge current of the battery must be known, as well as polarization resistance and ohmic resistance, etc. Calculating the total calorific value in this way will bring great calculation difficulties. Therefore, an index of heat generation rate is used to deal with the total heat of lithium iron phosphate batteries during discharge. Moreover, for the convenience of research and calculation, the heat generation of lithium iron phosphate batteries has been partially simplified. According to Bernardi's research hypothesis, we treat the heated battery as a uniform source of heat. At this time, the heat generation rate $q_{v}$ of the battery can be expressed by Equation (1) [27]: 


$$
q_{v}=\frac{1}{V_{\text {battery }}}\left[\left(E-U_{\text {battery }}\right)+T \frac{d E}{d T}\right]
$$

where $V_{\text {battery }}$ represents the volume of the battery, $\mathrm{m}^{3} ; E$ represents the electromotive force of the battery, $V ; U_{\text {battery }}$ represents the terminal voltage across the battery, $V ; T$ represents the temperature of the battery, $\mathrm{K} ; d E / d T$ represents the temperature influence coefficient, which is generally empirically constant in engineering applications.

\subsection{Single Battery Module Simulation Parameter Setting}

The physical characteristics of the prismatic lithium iron phosphate battery used in this paper are as follows.

(1) Density $\rho$

The density of the single prismatic battery used in this paper is $2840 \mathrm{~kg} / \mathrm{m}^{3}$.

(2) Specific heat capacity $c$

The simplified specific heat capacity calculation equation can be expressed as the weighted average of the specific heat capacity of each part of the battery; the equation is as follows [28]:

$$
c=\frac{1}{m_{a}} \sum_{1}^{i} c_{i} m_{i}
$$

where $c_{i}$ is the specific heat capacity of the different components of the battery; $m_{i}$ is the corresponding quality; $m_{a}$ is the overall quality of the battery. According to the above equation, the specific heat capacity of the single square battery used in this paper can be derived as $1020 \mathrm{~J} / \mathrm{kg} \cdot \mathrm{K}$.

(3) Thermal Conductivity

The thermal conductivity of a single prismatic battery is anisotropic, and the calculation equation is as follows [29]:

$$
\left\{\begin{array}{c}
\lambda_{x}=\frac{L}{\frac{d x_{1}}{\lambda_{1}}+\frac{d x_{2}}{\lambda_{2}}+\frac{d x_{3}}{\lambda_{3}}} \\
\lambda_{y}=\frac{\lambda_{1} d y_{1}+\lambda_{2} d y_{2}+\lambda_{3} d y_{3}}{b} \\
\lambda_{z}=\frac{\lambda_{1} d z_{1}+\lambda_{2} d z_{2}+\lambda_{3} d z_{3}}{h}
\end{array}\right.
$$

where $\lambda_{1}, \lambda_{2}, \lambda_{3}$ represent the thermal conductivity of the positive electrode, negative electrode and separator of the battery, respectively; $d x, d y, d z$ represent the thickness of different battery materials in these three directions, respectively; $L, b, h$ represent the total length, thickness and width of the battery, respectively, and these parameters are provided by the battery manufacturer. According to the above equation, the thermal conductivity of the power battery in the three directions is 1.1, 18.3 and 18.3.

\subsection{Simulation Discharge Analysis of a Single Battery Module}

\subsubsection{Discharge under Different Ambient Temperature Conditions}

In the previous section, the parameters of a single battery module have been set, and the meshing quality also meets the research requirements. We input the above parameters into Star $\mathrm{ccm}+$ to model and simulate a single battery module. Then, we discuss the temperature situation when a single battery module is discharged at the discharge rate of $1 \mathrm{C}$ under different ambient temperatures. The research mainly discusses the maximum temperature and temperature distribution. Then, we plot the temperature of the battery module at $15^{\circ} \mathrm{C}$ ambient temperature, $20^{\circ} \mathrm{C}$ ambient temperature, $25^{\circ} \mathrm{C}$ ambient temperature and $30^{\circ} \mathrm{C}$ ambient temperature, respectively, in Figures $2-5$. 


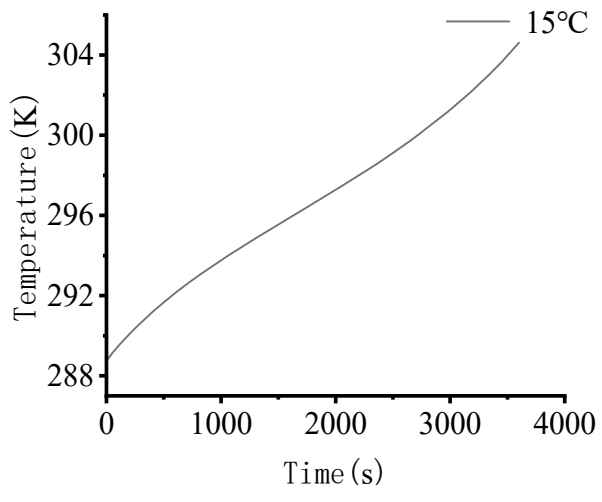

(a)

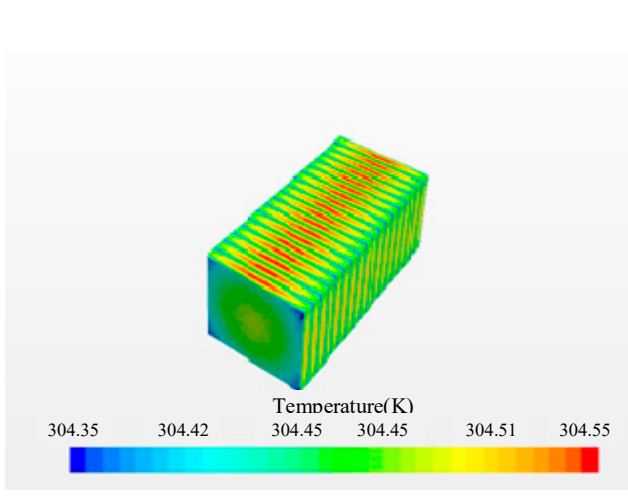

(b)

Figure 2. The temperature of the battery module at $15^{\circ} \mathrm{C}$. (a) Maximum temperature of a single module at $15{ }^{\circ} \mathrm{C}$. (b) Temperature distribution of a single module under $15^{\circ} \mathrm{C}$ discharge rate.

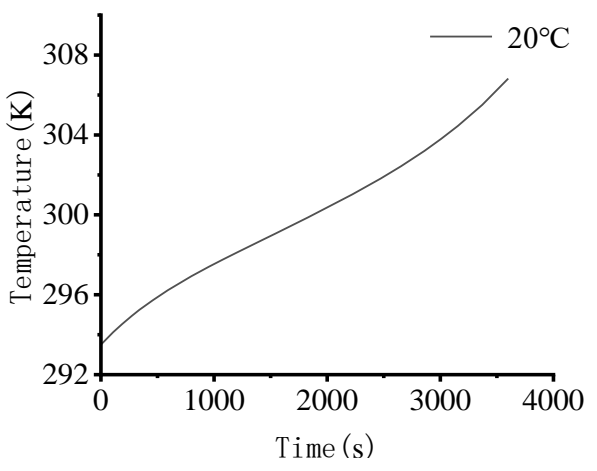

(a)

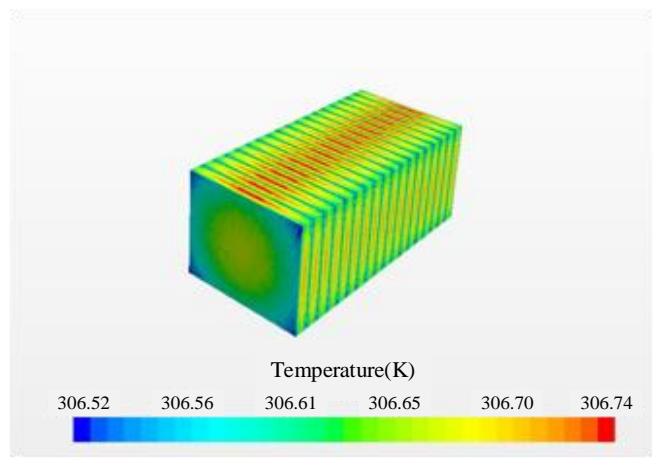

(b)

Figure 3. The temperature of the battery module at $20^{\circ} \mathrm{C}$. (a) Maximum temperature of a single module at $20^{\circ} \mathrm{C}$. (b) Temperature distribution of a single module under $20^{\circ} \mathrm{C}$ discharge rate.

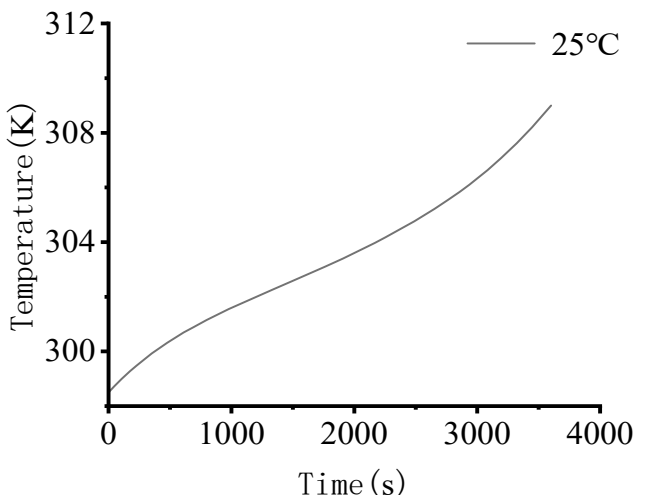

(a)

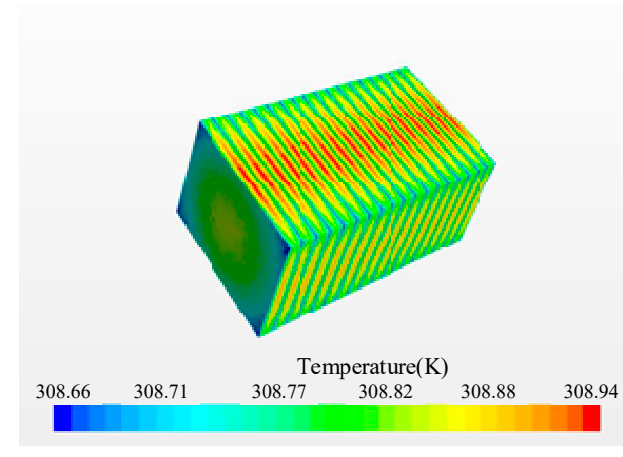

(b)

Figure 4. The temperature of the battery module at $25^{\circ} \mathrm{C}$. (a) Maximum temperature of a single module at $25^{\circ} \mathrm{C}$. (b) Temperature distribution of a single module under $25^{\circ} \mathrm{C}$ discharge rate. 


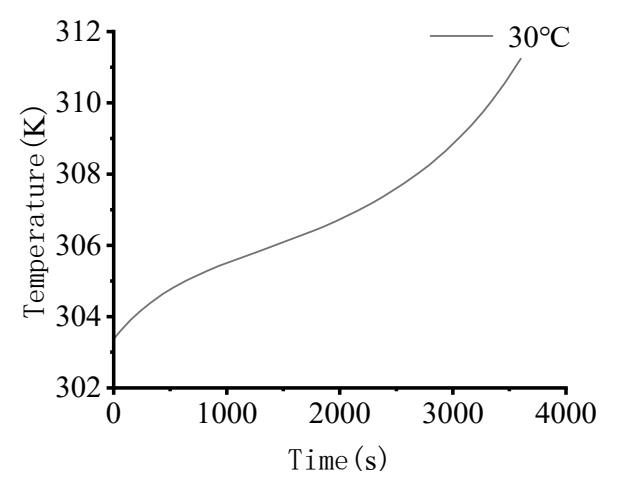

(a)

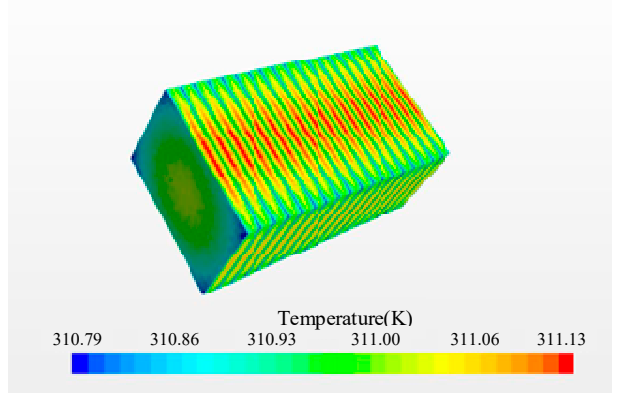

(b)

Figure 5. The temperature of the battery module at $30^{\circ} \mathrm{C}$. (a) Maximum temperature of a single module at $30{ }^{\circ} \mathrm{C}$. (b) Temperature distribution of a single module under $30^{\circ} \mathrm{C}$ discharge rate.

Figure 2 shows the temperature of the battery module at the ambient temperature of $15{ }^{\circ} \mathrm{C}$. It can be seen from Figure 2 that the maximum temperature of the battery module will first rise at a relatively fast rate. At approximately $1000 \mathrm{~s}$, the rate of the maximum temperature rise will decrease. When at approximately $2800 \mathrm{~s}$, the maximum temperature of the battery module will rise again at a relatively fast rate until the discharge stops. The temperature distribution law of the battery module is that the closer to the center of the module, the higher the temperature. This is because this area is not in direct contact with the air, which results in a poorer heat dissipation effect than at the surface. The temperature difference in the module is $0.2 \mathrm{~K}$.

Figure 3 shows the temperature of the battery module at the ambient temperature of $20^{\circ} \mathrm{C}$. It can be seen from Figure 3 that the maximum temperature of the battery module will first rise at a relatively fast rate. At approximately $750 \mathrm{~s}$, the maximum temperature rise rate decreases. At approximately $2900 \mathrm{~s}$, the maximum temperature of the battery module will rise again at a relatively fast rate until the discharge stops. The battery module temperature distribution law remains unchanged, and the temperature difference is $0.18 \mathrm{~K}$.

Figure 4 shows the temperature of the battery module at an ambient temperature of $25{ }^{\circ} \mathrm{C}$. The maximum temperature trend of the battery module is similar to that at the ambient temperature of $20^{\circ} \mathrm{C}$. It can be seen from Figure 4 that the maximum temperature of the battery module will first rise at a relatively fast rate. At approximately $650 \mathrm{~s}$, the maximum temperature rise rate decreases. At approximately $2500 \mathrm{~s}$, the maximum temperature of the battery module will rise again at a relatively fast rate until the discharge stops. The battery module temperature distribution law remains unchanged, and the temperature difference is $0.28 \mathrm{~K}$.

Figure 5 shows the temperature of the battery module at an environmental temperature of $30^{\circ} \mathrm{C}$. Figure 5 illustrates that the greatest temperature change in the battery module is similar to that at the environmental temperature of $20^{\circ} \mathrm{C}$ and at the environmental temperature of $25^{\circ} \mathrm{C}$. However, at approximately $2300 \mathrm{~s}$, the highest temperature of the battery module will rise at a relatively fast rate, and this rate is much faster than the rate under the first three environmental temperatures. The battery module temperature distribution law remains unchanged, and the temperature difference is $0.34 \mathrm{~K}$.

By comparing the data in Figures 2-5, it can be found that the maximum temperature variation in the individual battery modules is almost the same at different ambient temperatures, and the temperature distribution of a single module is also substantially similar.

\subsubsection{Discharge under Different Discharge Rates}

This section studies the temperature of a single battery module under different discharge rates at room temperature. We evaluate a single module discharge at $1 \mathrm{C}, 2 \mathrm{C}, 3 \mathrm{C}$. The temperature of the module is shown in Figures 6-8. 


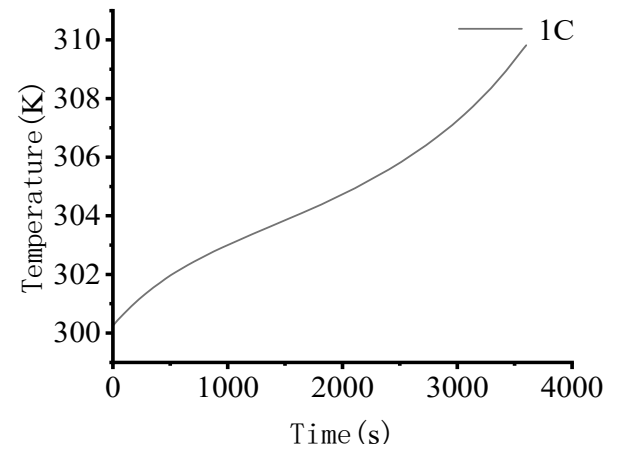

(a)

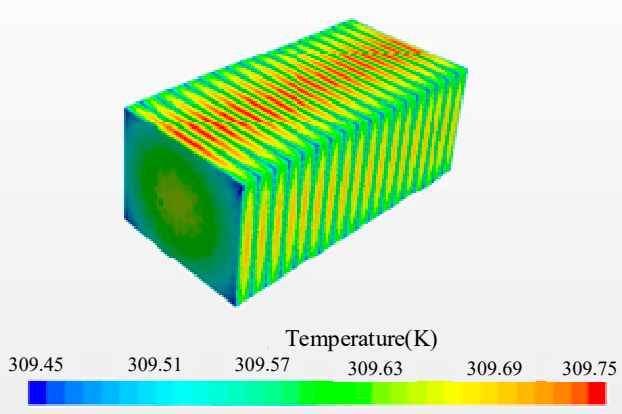

(b)

Figure 6. The temperature of the battery module under $1 \mathrm{C}$ discharge rate. (a) Maximum temperature of a single battery module under $1 \mathrm{C}$ discharge rate. (b) Temperature distribution of a single module under $1 \mathrm{C}$ discharge rate.

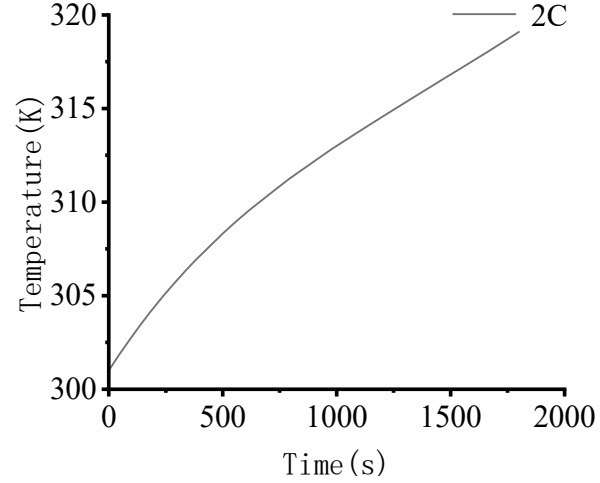

(a)

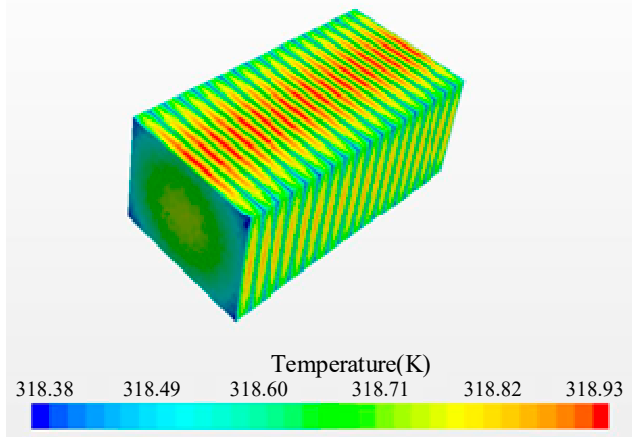

(b)

Figure 7. The temperature of the battery module under $2 \mathrm{C}$ discharge rate. (a) Maximum temperature of a single battery module under $2 \mathrm{C}$ discharge rate. (b) The temperature of the battery module under $2 \mathrm{C}$ discharge rate.

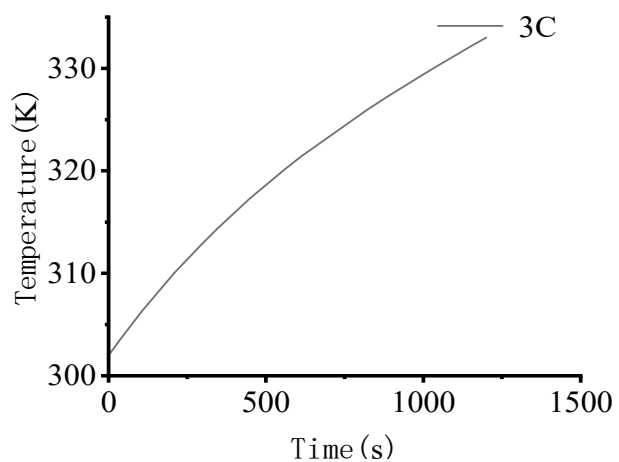

(a)

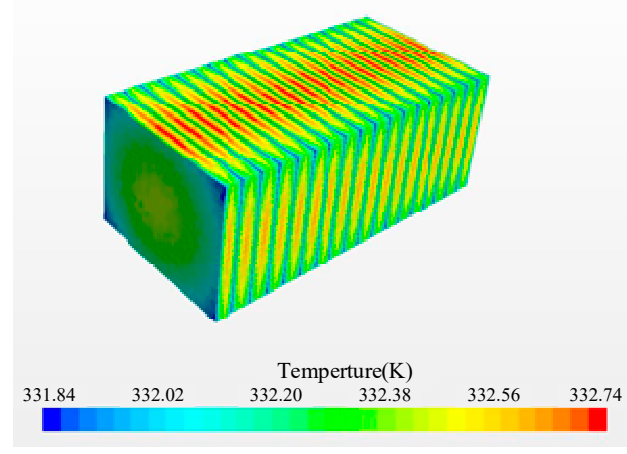

(b)

Figure 8. The temperature of the battery module under $3 \mathrm{C}$ discharge rate. (a) Maximum temperature of a single battery module under $3 \mathrm{C}$ discharge rate. (b) The temperature of the battery module under $3 \mathrm{C}$ discharge rate.

It can be seen from Figure 6 that the maximum temperature of the battery module first rises at a faster rate when a single battery module is discharged at a discharge rate of $1 \mathrm{C}$. Then, the rate of ascent slows down, and finally it rises at a faster rate. At $3600 \mathrm{~s}$, the maximum temperature of the battery module can reach approximately $309.5 \mathrm{~K}$. At this time, 
the temperature difference in the entire battery module is within $0.5 \mathrm{~K}$. Moreover, it can be seen from the temperature distribution diagram of the battery module that the temperature of the battery at the head and tail of the module is relatively low. In comparison, the temperature of the battery in the middle of the module is higher, and the temperature in the area closer to the center is higher, while the temperature in the area farther from the center is lower.

It can be seen from Figure 7 that after a single battery module is discharged at the discharge rate of $2 \mathrm{C}$ for $1800 \mathrm{~s}$, the maximum temperature can reach approximately $319 \mathrm{~K}$, which is around $10 \mathrm{~K}$ higher than the maximum temperature when discharged at the rate of $1 \mathrm{C}$. It can be seen from Figure 8 that after a single battery module is discharged at the discharge rate of $3 \mathrm{C}$ for $1200 \mathrm{~s}$, the maximum temperature can reach approximately $335 \mathrm{~K}$, which is around $25 \mathrm{~K}$ higher than the maximum temperature when discharged at the rate of $1 \mathrm{C}$. It can also be seen that the law of the battery module temperature distribution graph under $2 \mathrm{C}$ and $3 \mathrm{C}$ discharge rates is the same as that of $1 \mathrm{C}$.

\section{Liquid Cooling}

\subsection{Liquid-Cooled Cooling Model Establishment}

Geometric modeling of liquid cooling models was performed using Solidworks. Figure 9 shows the liquid cooling model of the battery pack. The liquid cooling module is composed of two vertical cooling plates and one cooling bottom plate. The battery pack is evenly arranged on the cooling bottom plate and wrapped by two vertical cooling plates. The vertical cooling plate has a thickness of $10 \mathrm{~mm}$ and contains a right-angle cooling pipe with a diameter of $8 \mathrm{~mm}$. The thickness of the cooling bottom plate is $30 \mathrm{~mm}$, and it contains a snake-shaped cooling pipe with a diameter of $28 \mathrm{~mm}$.

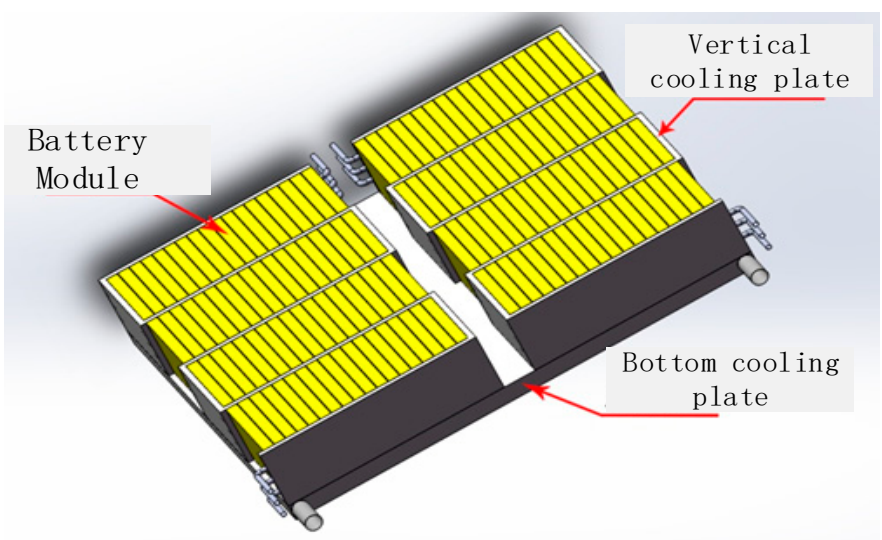

Figure 9. Simplified geometric diagram of liquid-cooled battery module.

\subsection{Discharge under Different Discharge Rates}

In this section, Scheme I is adopted, i.e., the cooling scheme of the cooling bottom plate containing one snake-shaped cooling channel and two vertical cooling plates each containing three cooling channels, to study the temperature of the battery pack after cooling by the coolant under the condition of different discharge rates. The cooling liquid inlet and outlet of the cooling bottom plate are set to left-in and right-out. Figure 10 shows the temperature distribution results, and Figure 11 shows the maximum temperature results.

It can be seen from Figures 10 and 11 that, in Scheme I, when the battery pack is discharged at the rate of $1 \mathrm{C}$ and $2 \mathrm{C}$, the maximum temperature of the battery pack is approximately $304.7 \mathrm{~K}$ and $308 \mathrm{~K}$, respectively, and the temperature difference in the battery pack is around $3.8 \mathrm{~K}$ and $5.3 \mathrm{~K}$, respectively. This shows that the battery pack is discharged at these two rates, and the maximum temperature after cooling by the cooling module is ideal; the temperature uniformity is also relatively good. When the battery pack is discharged at the rate of $3 \mathrm{C}$ and $4 \mathrm{C}$, the maximum temperature of the battery pack is approximately $316.7 \mathrm{~K}$ and $329.8 \mathrm{~K}$, respectively, and the temperature difference in the 
battery pack is around $15.2 \mathrm{~K}$ and $25.8 \mathrm{~K}$, respectively. In these two cases, the temperature of the battery pack is not ideal and needs further control. By comparing these four cases, the following conclusions can be obtained: as the discharge rate increases, the maximum temperature of the battery pack will also increase, the temperature uniformity will become worse, and the cooling effect of the liquid cooling module will become worse.

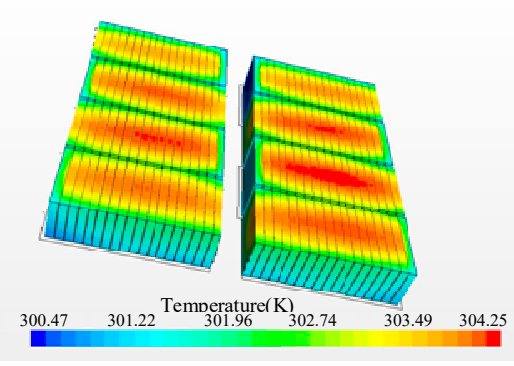

(a)

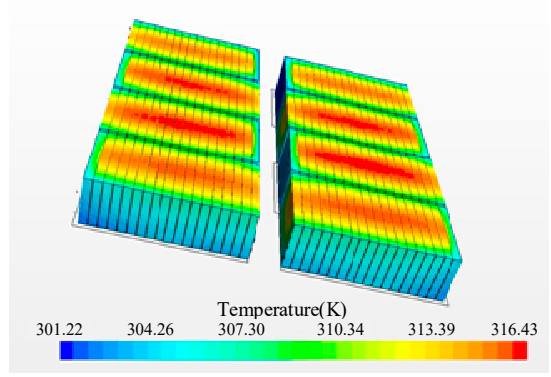

(c)

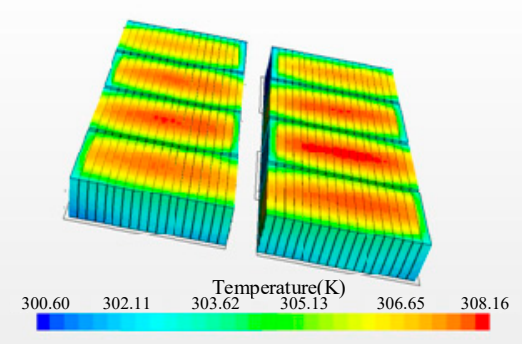

(b)

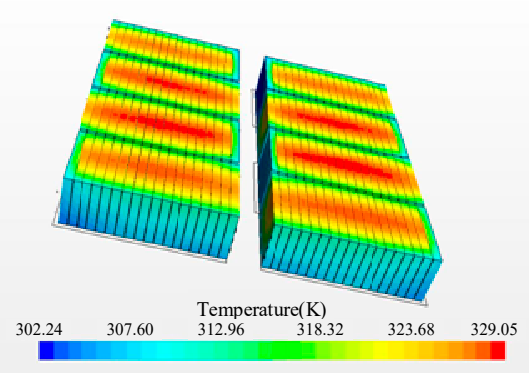

(d)

Figure 10. Temperature field of battery modules with different magnifications in Scheme I. (a) Temperature distribution of battery pack under $1 \mathrm{C}$ rate. (b) Temperature distribution of battery pack under $2 \mathrm{C}$ rate. (c) Temperature distribution of battery pack under $3 \mathrm{C}$ rate. (d) Temperature distribution of battery pack under $4 \mathrm{C}$ rate.

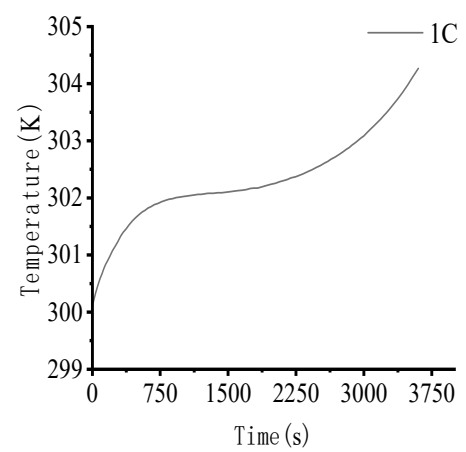

(a) Maximum temperature under $1 \mathrm{C}$ rate.

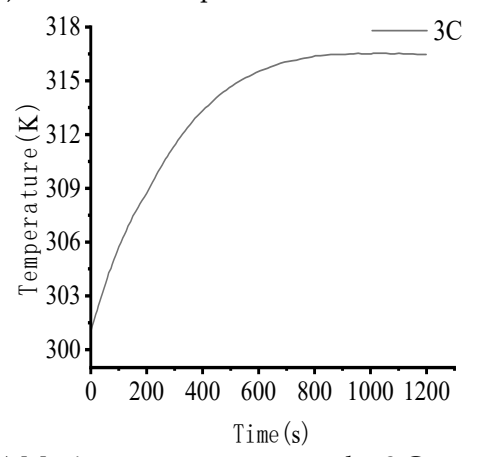

(c) Maximum temperature under $3 \mathrm{C}$ rate.

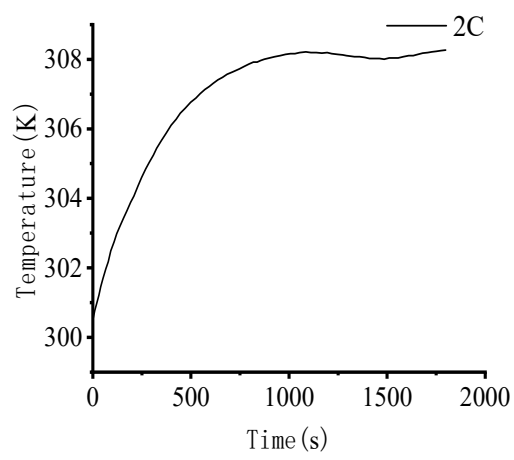

(b) Maximum temperature under $2 \mathrm{C}$ rate.

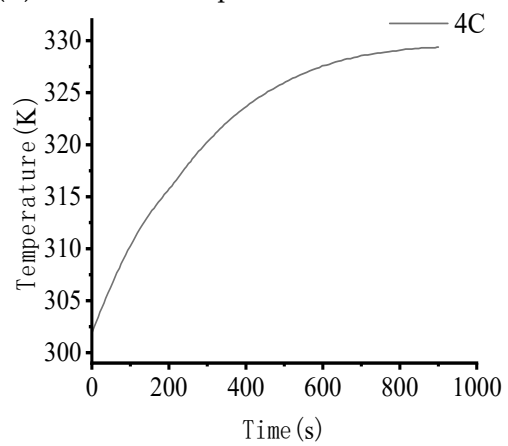

(d) Maximum temperature under $4 \mathrm{C}$ rate.

Figure 11. Maximum temperature of battery modules with different magnifications in Scheme I. 


\subsection{Discharge under Different Coolant Speed Conditions}

After the research in the previous section, it is found that when the battery pack is discharged at a $1 \mathrm{C}$ or $2 \mathrm{C}$ rate, the maximum temperature does not exceed $308 \mathrm{~K}$, and the temperature uniformity is also good. Therefore, we do not discuss these two situations further. In order to improve the cooling effect of the cooling module when the battery pack is discharged at a rate of $3 \mathrm{C}$ and $4 \mathrm{C}$ in the first solution, the second solution is adopted. Specifically, the cooling liquid inlet flow rate setting method is modified as follows: when the maximum temperature of the battery pack is lower than $308 \mathrm{~K}$, the coolant inlet flow rate is $0.3 \mathrm{~m} / \mathrm{s}$, and when the maximum temperature of the battery pack is higher than $308 \mathrm{~K}$, the coolant inlet flow rate is $0.8 \mathrm{~m} / \mathrm{s}$. The order of the inlet and outlet of the coolant remains unchanged. Figure 12 shows the temperature distribution results; Figure 13 shows the maximum temperature results.

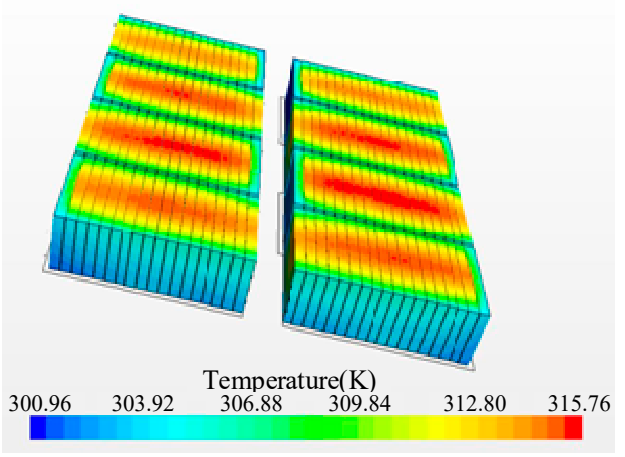

(a)

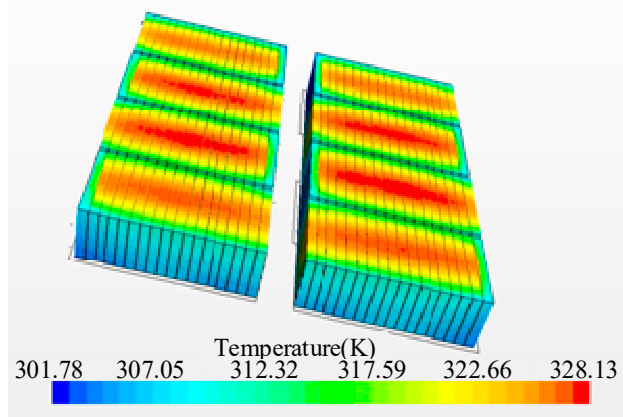

(b)

Figure 12. Temperature field of battery modules with different magnifications in Scheme II. (a) Temperature distribution of battery pack under $3 \mathrm{C}$ rate. (b) Temperature distribution of battery pack under $4 \mathrm{C}$ rate.

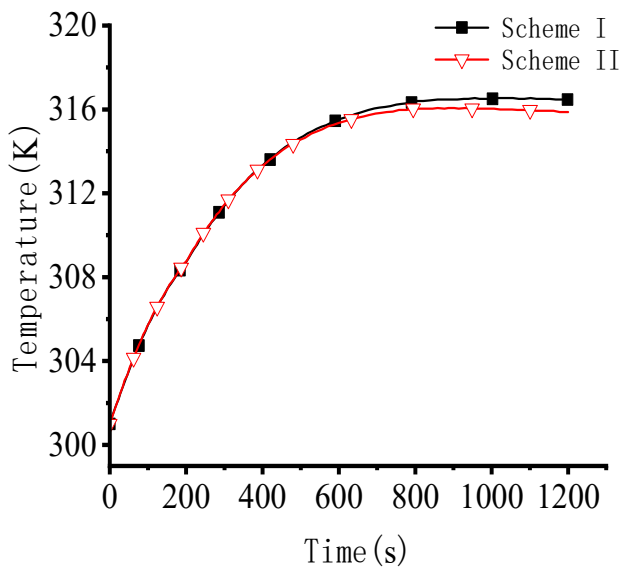

(a)

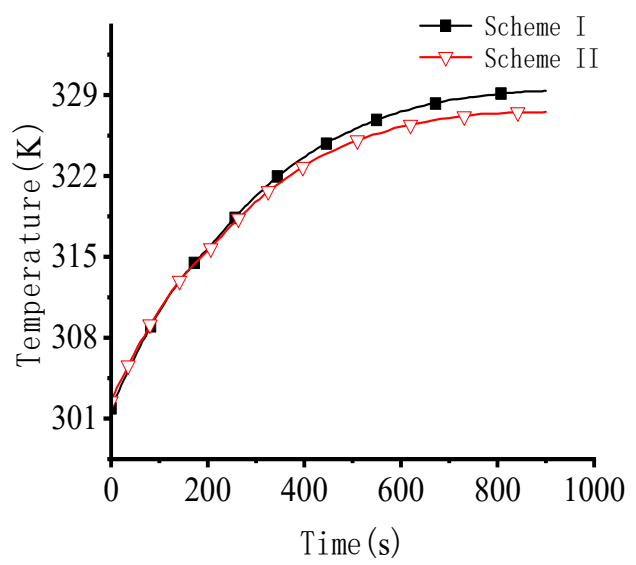

(b)

Figure 13. Comparison of the maximum temperature of battery modules in different schemes. (a) The maximum temperature of the battery pack under $3 \mathrm{C}$ magnification. (b) The maximum temperature of the battery pack under $4 \mathrm{C}$ magnification.

In order to compare the effects of the two schemes more intuitively, we compare Scheme I with Scheme II. Figures 13 and 14 show the comparison results.

Figure 13 shows that, compared to the first solution, increasing the coolant inlet flow rate can effectively improve the cooling effect of the cooling module when the maximum temperature of the battery pack is higher than $308 \mathrm{~K}$. It can also be seen that the maximum temperature of the battery pack in Scheme II is around $0.8 \mathrm{~K}$ lower than the maximum temperature of the battery pack in Scheme I when the battery pack is discharged at a 
discharge rate of $3 \mathrm{C}$. The maximum temperature of the battery pack in Scheme II is around $1.8 \mathrm{~K}$ lower than that in Scheme I when the battery pack is discharged at a discharge rate of 4 C. Moreover, the cooling effect in Scheme II is improved. The maximum temperature of the battery pack has been improved. It can be seen from Figure 14 that, compared to Scheme I, the temperature difference in the battery pack in Scheme II is reduced by approximately $0.4 \mathrm{~K}$ compared with the temperature difference in the battery pack in Scheme I when the battery pack is discharged at a discharge rate of $3 \mathrm{C}$. When the battery pack is discharged at $4 \mathrm{C}$, the temperature difference in the battery pack in Scheme II is reduced by around $2.5 \mathrm{~K}$ compared with the temperature difference in the battery pack in Scheme I, and the cooling effect in Scheme II is improved. The temperature distribution of the battery pack under the two different discharge rates has been improved. In summary, Scheme II can improve the cooling effect of the liquid cooling module. In order to achieve a better cooling effect that is in line with actual requirements, the second solution is further studied.

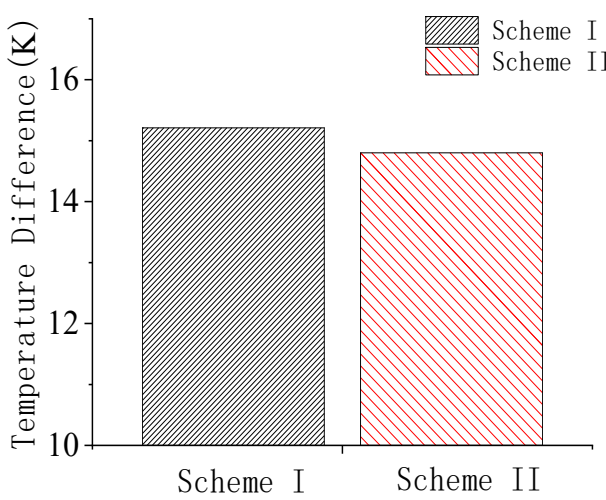

(a)

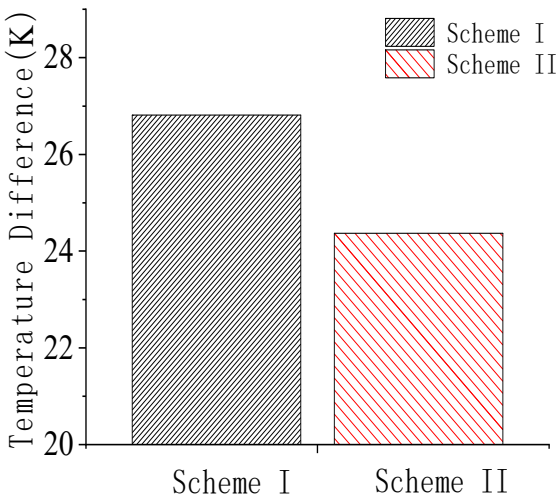

(b)

Figure 14. Comparison of the temperature difference of battery modules in different schemes. (a) Temperature difference in battery pack under $3 \mathrm{C}$ magnification. (b) Temperature difference in battery pack under $4 \mathrm{C}$ magnification.

\subsection{Discharge under Different Numbers of Cooling Channels in the Vertical Cooling Plate}

The liquid-cooled cooling modules adopted in Scheme I and Scheme II are composed of two vertical cooling plates and one cooling bottom plate. Two of the vertical cooling plates each contain three right-angle cooling channels, and the cooling bottom plate contains one snake-shaped cooling channel. In order to further study the influence of the number of different cooling channels on the temperature of the battery pack, this section proposes Scheme III and Scheme IV These two new schemes increase the number of right-angle cooling channels contained in two vertical cooling plates. The liquid-cooled cooling module of Scheme III includes two vertical cooling plates that each contain four right-angle cooling channels, and the cooling bottom plate contains one snake-shaped cooling channel. The liquid-cooled cooling module of Scheme IV includes two vertical cooling plates that each contain five right-angle cooling channels, and the cooling bottom plate contains one snakeshaped cooling channel, while the other conditions remain unchanged. The schematic diagram is shown in Figure 15.

From the research in the previous section, it is noted that increasing the coolant inlet flow rate can effectively improve the cooling effect of the cooling module, reduce the maximum temperature of the battery pack and improve the temperature uniformity. Therefore, in this section, an increased coolant inlet flow rate setting and coolant inlet and outlet sequence setting are adopted, and the remaining boundary conditions remain unchanged. The temperature distribution and maximum temperature of the battery pack under the $3 \mathrm{C}$ and $4 \mathrm{C}$ discharge rates of Scheme III and Scheme IV are studied. 
In order to compare the maximum temperature of the battery pack more intuitively, this paper plots the maximum temperature of the battery pack for the four scenarios at $3 \mathrm{C}$ and $4 \mathrm{C}$ discharge rates in Figure 16.

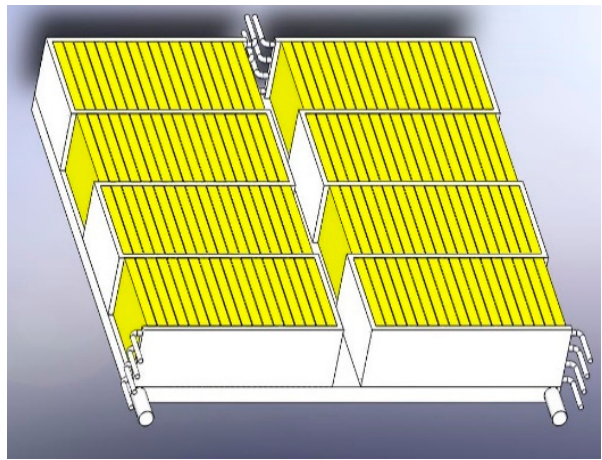

(a) scheme III

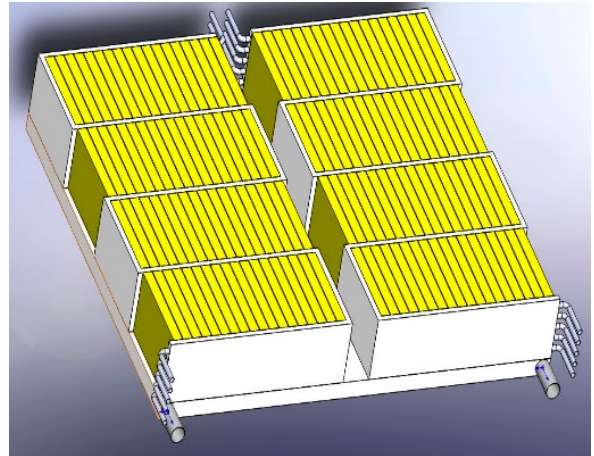

(b) scheme IV

Figure 15. Vertical cooling plate containing different numbers of cooling pipes.

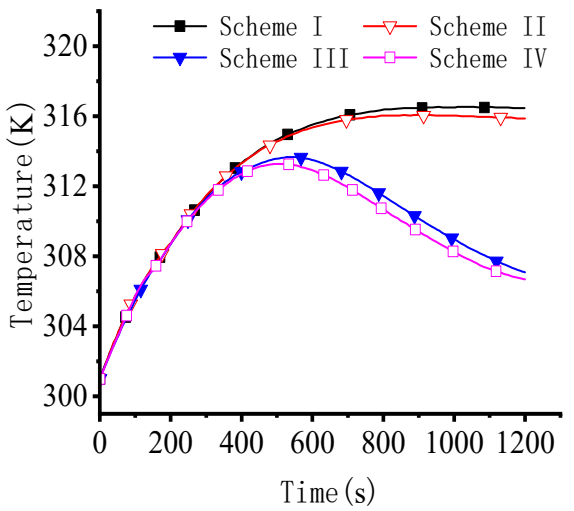

(a)

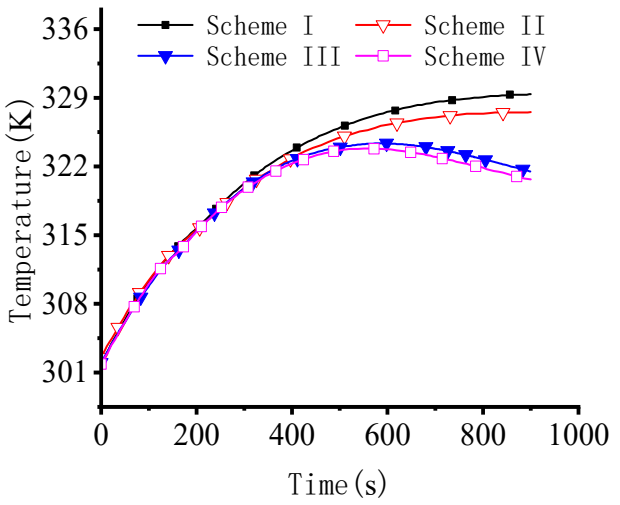

(b)

Figure 16. Comparison of the maximum temperature of battery modules in different schemes. (a) The maximum temperature of the battery pack under $3 \mathrm{C}$ magnification. (b) The maximum temperature of the battery pack under $3 \mathrm{C}$ magnification.

It can be seen from Figure 16 that increasing the number of right-angle cooling channels in the vertical cooling plate can effectively reduce the maximum temperature of the battery pack, and the more right-angle cooling channels contained in the vertical cooling plate, the better the maximum temperature control. The maximum temperature of the battery packs in Scheme I and Scheme II continues to increase and finally stabilizes at a certain value. In comparison, Scheme III and Scheme IV can reduce the maximum temperature of the battery pack after reaching the peak value. This means that the cooling performance of these two schemes is better than that of Scheme Iand Scheme II, and the cooling effect of Scheme IV is better than that of Scheme III. However, it can also be seen that the cooling performance of Scheme IV is only slightly better than that of Scheme III. In other words, increasing the number of cooling pipes will no longer have a significant impact on the improvement in cooling performance when the number of cooling pipes in the vertical cooling plate is greater than five. Thus, it will not be discussed further when the number of cooling pipes in the vertical cooling plate is more than five.

\subsection{Discharge under Different Numbers of Cooling Channels in the Cooling Bottom Plate}

Scheme V consists of two vertical cooling plates and one cooling bottom plate. Both vertical cooling plates contain three right-angle cooling pipes, and the cooling bottom plate contains two snake-shaped pipes. The cooling module of Scheme VI includes two vertical 
cooling plates and one cooling bottom plate. Both vertical cooling plates contain four right-angle pipes, and the cooling bottom plate contains two snake-shaped cooling pipes. The cooling module of Scheme VII consists of two vertical cooling plates and one cooling bottom plate. The two vertical cooling plates contain five right-angle cooling pipes, and the cooling bottom plate contains two snake-shaped cooling pipes. The schematic diagram is shown in Figure 17.

The remaining boundary conditions and the order of the coolant inlet and outlet remain unchanged, and a larger coolant inlet flow rate setting is selected. The temperature distribution and maximum temperature of the battery pack under the $3 \mathrm{C}$ and $4 \mathrm{C}$ discharge rates of these three schemes are studied and the temperature distribution and maximum temperature of Scheme IV are compared to those of Scheme VII. Figure 18 shows the maximum temperature comparison of these four schemes.

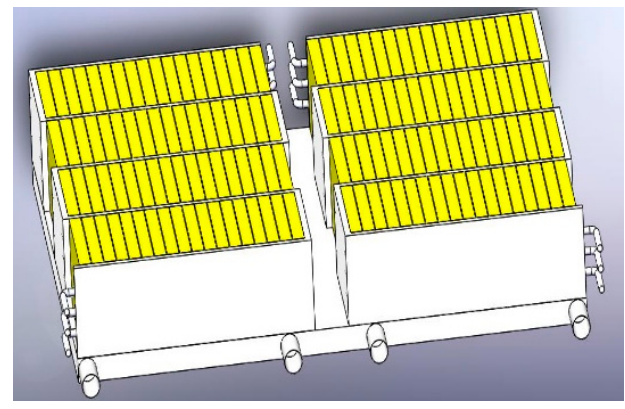

(a) Scheme V

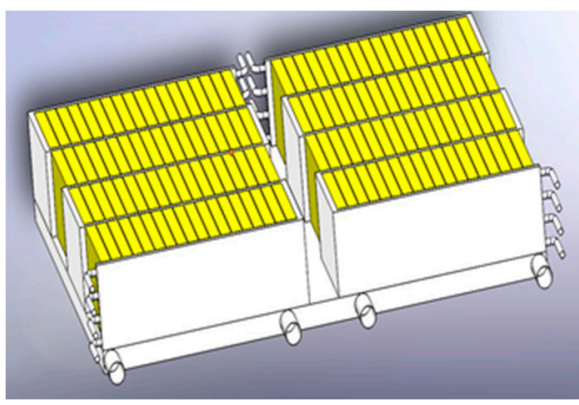

(b) Scheme VI

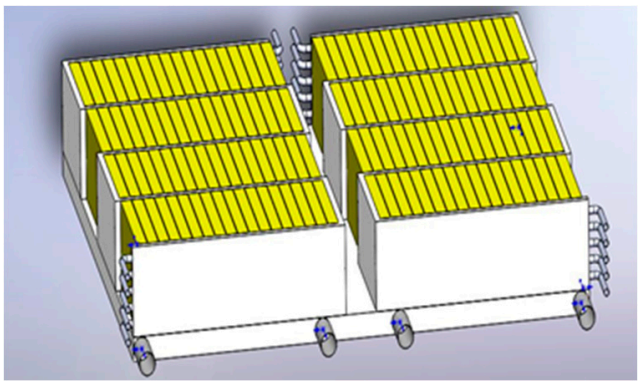

(c) Scheme VII

Figure 17. Different schemes.

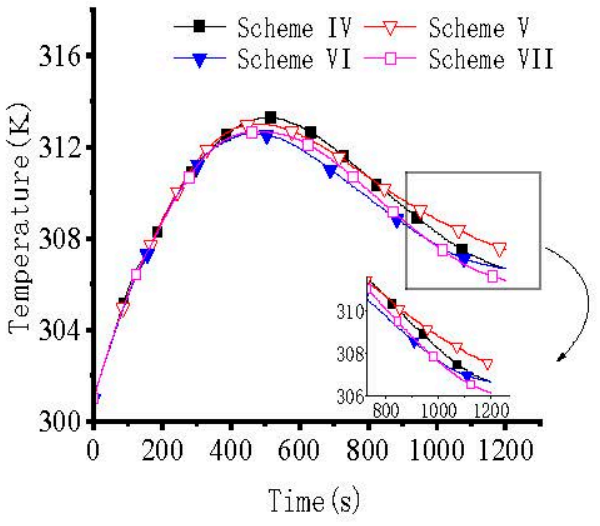

(a)

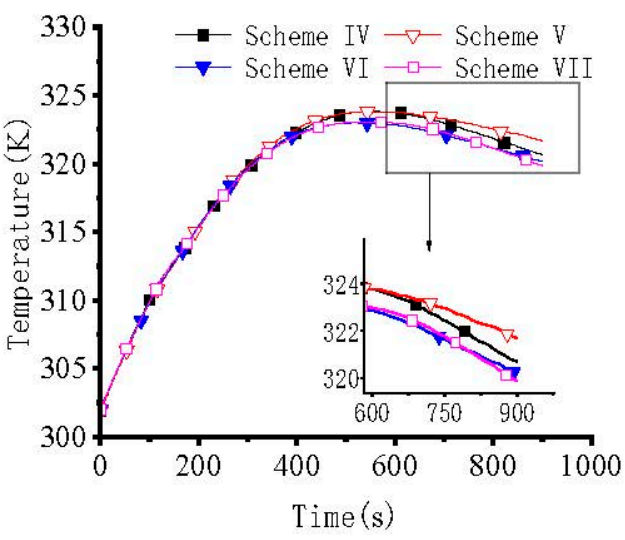

(b)

Figure 18. Comparison of the maximum temperature of battery modules in different schemes. (a) The maximum temperature of the battery pack under $3 \mathrm{C}$ magnification. (b) The maximum temperature of the battery pack under $4 \mathrm{C}$ magnification. 
It can be seen from Figure 18 that there is almost no significant difference in the cooling effect of Scheme IV in the interval of $0-500 \mathrm{~s}$ when the battery pack is discharged at a rate of $3 \mathrm{C}$. The maximum temperature of the battery pack continues to rise and reaches a peak. The maximum temperature of the battery pack begins to decrease under the action of the cooling module in the interval of 500-1200 s. Moreover, compared to Scheme V and Scheme V, the cooling effect of Scheme VI and Scheme VII is better. Moreover, the maximum temperature curves of these two schemes almost overlap, and it can be considered that the cooling effects of these two schemes are almost the same.

\subsection{Response Surface Optimization}

The test data adopt the recorded value of the Starccm + simulation result to observe the influence of the cooling pipe diameter, the temperature of the coolant and the thermal conductivity of the material on the temperature field of the power battery pack. When using the BBD test method in the Design Expert software for the design, we set the cooling pipe diameter, coolant temperature and material thermal conductivity as three independent variables, which are represented by A, B and C. The specific content is shown in Table 1 below.

Table 1. Factors of tested independent variables.

\begin{tabular}{cccccc}
\hline Parameter & Units & Code & \multicolumn{3}{c}{ Factor Level } \\
\hline Cooling pipe diameter value & $\mathrm{mm}$ & $\mathrm{A}$ & 7.5 & 8 & 8.5 \\
Coolant temperature & ${ }^{\circ} \mathrm{C}$ & $\mathrm{B}$ & 5 & 10 & 15 \\
Material thermal & $(\mathrm{W} /(\mathrm{m} \cdot \mathrm{K}))$ & $\mathrm{C}$ & 4.5 & 5 & \\
Conductivity & & & & \\
\hline
\end{tabular}

After determining the independent variables and factor levels of the scheme, we then use the temperature equilibrium degree $\mathrm{M}$ of the power battery pack as the dependent variable. We enter the value of the dependent variable under different independent variables in the simulation results obtained by Starccm+ into Design Expert, as shown in Table 2 below.

Table 2. Factors of tested independent variables.

\begin{tabular}{ccccc}
\hline Test Number & $\begin{array}{c}\text { Cold Tube } \\
\text { Diameter/mm }\end{array}$ & $\begin{array}{c}\text { Coolant } \\
\text { Temperature }\end{array}$ & $\begin{array}{c}\text { Thermal Con- } \\
\text { ductivity/W/mK }\end{array}$ & $\begin{array}{c}\text { Temperature } \\
\text { Equilibrium M(\%) }\end{array}$ \\
\hline 1 & 7.5 & 5 & 4.5 & 97.45 \\
2 & 8 & 5 & 4.5 & 93.42 \\
3 & 8.5 & 5 & 4.5 & 93.50 \\
4 & 7.5 & 10 & 4.5 & 97.48 \\
5 & 8 & 10 & 4.5 & 94.32 \\
6 & 8.5 & 10 & 4.5 & 94.27 \\
7 & 7.5 & 15 & 4.5 & 97.48 \\
8 & 8 & 15 & 4.5 & 94.93 \\
9 & 8.5 & 15 & 4.5 & 94.98 \\
10 & 7.5 & 5 & 5 & 97.45 \\
11 & 8 & 5 & 5 & 93.42 \\
12 & 8.5 & 5 & 5 & 93.49 \\
13 & 7.5 & 10 & 5 & 97.51 \\
14 & 8 & 10 & 5 & 94.17 \\
15 & 8.5 & 10 & 5 & 94.25 \\
16 & 7.5 & 15 & 5 & 97.48 \\
17 & 8.5 & 15 & 5 & 94.99 \\
\hline
\end{tabular}

The regression equation model is as follows:

$$
\begin{gathered}
M=94.18-1.61 A+0.4698 B-0.0312 C+0.3650 A B-0.0042 A C- \\
0.0335 B C+1.73 A^{2}-0.0752 B^{2}
\end{gathered}
$$


In the simulation analysis of the Design Expert software, the regression Equation (4) is used to solve the maximum value, and the following data are obtained: when the diameter of the cooling pipe is $7.5 \mathrm{~mm}$, the coolant temperature is $10.888^{\circ} \mathrm{C}$, and the thermal conductivity of the material is $4.956 \mathrm{~W} /(\mathrm{m} \cdot \mathrm{K})$; thus, the predicted value of the temperature equilibrium $\mathrm{M}$ of the power battery pack is $97.512 \%$, which is the maximum value of these data.

In this section, the diameter of the cooling channel, coolant temperature and thermal conductivity of the material are the three independent variables. Table 3 shows the results of the regression model analysis of variance with the temperature equilibrium degree $M$ as the dependent variable.

Table 3. Variance analysis of regression models.

\begin{tabular}{cccccc}
\hline Factor & $\begin{array}{c}\text { Sum of } \\
\text { Square }\end{array}$ & $\begin{array}{c}\text { Degree of } \\
\text { Freedom }\end{array}$ & $\begin{array}{c}\text { Mean } \\
\text { Square }\end{array}$ & F & $p$ \\
\hline Model & 46.41 & 8 & 5.80 & 163.59 & $<0.0001$ \\
A-A & 31.27 & 1 & 31.27 & 881.67 & $<0.0001$ \\
B-B & 2.32 & 1 & 2.32 & 65.36 & $<0.0001$ \\
C-C & 0.0160 & 1 & 0.0160 & 0.4516 & 0.5205 \\
AB & 1.07 & 1 & 1.07 & 30.05 & 0.0006 \\
AC & 0.0002 & 1 & 0.0002 & 0.0059 & 0.9408 \\
BC & 0.0118 & 1 & 10.09 & 0.3321 & 0.5803 \\
$\mathrm{~A}^{2}$ & 10.09 & 1 & 0.0216 & 0.6082 & $<0.0001$ \\
$\mathrm{~B}^{2}$ & 0.0216 & 1 & & & 0.4579 \\
$\mathrm{C}^{2}$ & 0.0000 & 0 & 0.0355 & & \\
Residual & 0.2837 & 8 & 16 & & \\
Total error & 46.69 & $\mathrm{R}^{2}=0.9939 \mathrm{R}_{\text {adj }}^{2}$ & 0.9878 & & \\
\hline
\end{tabular}

It can be seen from Table 4 that the $p$ value of the model is less than 0.0001 , which means that the model is extremely significant. The correlation coefficient $R^{2}$ is 0.9939 , and $\mathrm{R}_{\text {adj }}^{2}$ is 0.9878 . The values of these two coefficients indicate that the regression model designed by the response surface method is effective. It can also be seen that the order of influence of the three single factors on the temperature equilibrium degree $\mathrm{M}$ of the power battery pack is $\mathrm{A}>\mathrm{B}>\mathrm{C}$. The diameter of the cooling pipe has the greatest influence, the temperature of the coolant has a moderate influence, and the thermal conductivity of the material has the least influence.

Table 4. Properties of mixed solutions.

\begin{tabular}{|c|c|c|c|c|}
\hline Material & Viscosity/Pa.s & Density $/ \mathrm{kg} / \mathrm{m}^{3}$ & $\begin{array}{c}\text { Specific Heat } \\
\text { Capacity/J/(kg·K) }\end{array}$ & $\begin{array}{c}\text { Thermal } \\
\text { Conductivity } \\
\text { /W/(m.K) }\end{array}$ \\
\hline $\begin{array}{c}50 \% \text { mixed } \\
\text { solution }\end{array}$ & 0.00256 & 1066.27 & 3339 & 0.391 \\
\hline $\begin{array}{c}60 \% \text { mixed } \\
\text { solution }\end{array}$ & 0.00329 & 1078.71 & 3149 & 0.358 \\
\hline $\begin{array}{l}70 \% \text { mixed } \\
\text { solution }\end{array}$ & 0.00442 & 1090.43 & 2951 & 0.329 \\
\hline
\end{tabular}

Figure 19 shows the normal distribution of residuals and a comparison between residuals and experimental predictions. 


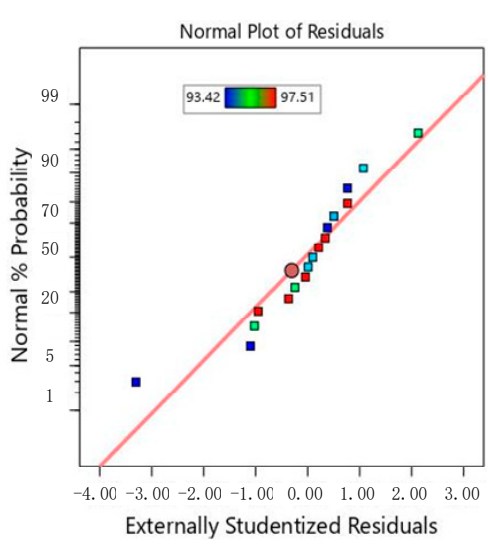

(a)

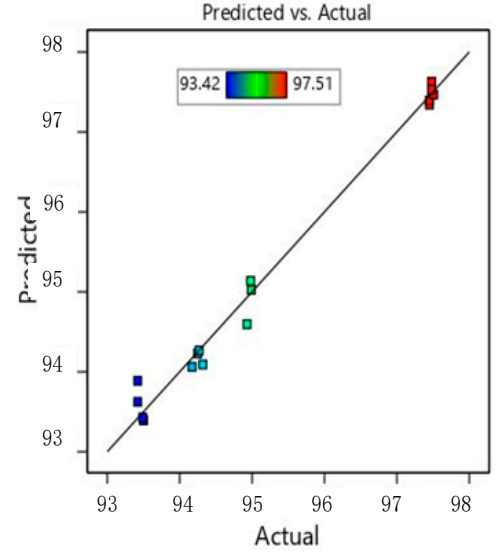

(b)

Figure 19. Schematic diagram of model reliability analysis. (a) The normal probability distribution plot of the residuals. (b) Comparison chart of predicted values and actual test values.

\section{Battery Pack Model Preheating Analysis}

Electric vehicles not only need to cool down the battery pack while driving, but also need to consider their working conditions in cold areas. When starting directly under low-temperature conditions, due to the reduction in the voltage platform and discharge capacity of the lithium-ion battery, the charging and discharging speed of the battery pack will be reduced, in addition to the problem of battery capacity attenuation. Therefore, the power battery pack must be preheated for electric vehicles under low-temperature working conditions. This section adopts the six geometric structures of the optimal cooling performance among the seven cooling schemes proposed in Section 3 and conducts the preheating research of the battery pack on this basis. By studying the preheating of the battery pack under different conditions of the preheating model, a preheating plan with better preheating performance is obtained. The structure optimization and response surface analysis of the preheating scheme are carried out, and the preheating scheme with the best temperature equilibrium degree is obtained.

\subsection{Different Preheating Fluid Properties}

This paper first adopts the following materials: the preheating liquid in the preheating pipeline is mixed with $50 \%$ ethylene glycol and $50 \%$ aqueous solution, and the specific material property parameters of 50\% water and 50\% ethylene glycol solution are shown in Table 4 . The temperature of the hydrothermal fluid is $35^{\circ} \mathrm{C}$. The materials of the two vertical plates and the bottom plate remain unchanged; the battery materials are also unchanged. The ambient temperature is set to $-15^{\circ} \mathrm{C}$. The heat exchange method between the two vertical plates, the bottom plate and the surface of the battery pack and the external environment are environmental heat exchange. The heat transfer coefficient is $5 \mathrm{~W} /\left(\mathrm{m}^{2} \cdot \mathrm{K}\right)$, and the temperature is consistent with the ambient temperature. The inlet of the preheating pipe is set as the speed inlet, the outlet is set as the pressure outlet, and the initial velocity of the preheating liquid is set to $0.5 \mathrm{~m} / \mathrm{s}$.

Figure 20 shows the preheating performance of the battery packs using the three different concentrations of preheating solution at an ambient temperature of $-15^{\circ} \mathrm{C}$. It can be seen that the $50 \%$ concentration of mixed solution is used as the preheating solution. It has better preheating performance. Compared with the 70\% mixed solution, when the $50 \%$ concentration mixed solution is used as the preheating solution, the temperature of the lowest-temperature part of the battery pack can be increased by approximately $3 \mathrm{~K}$. 


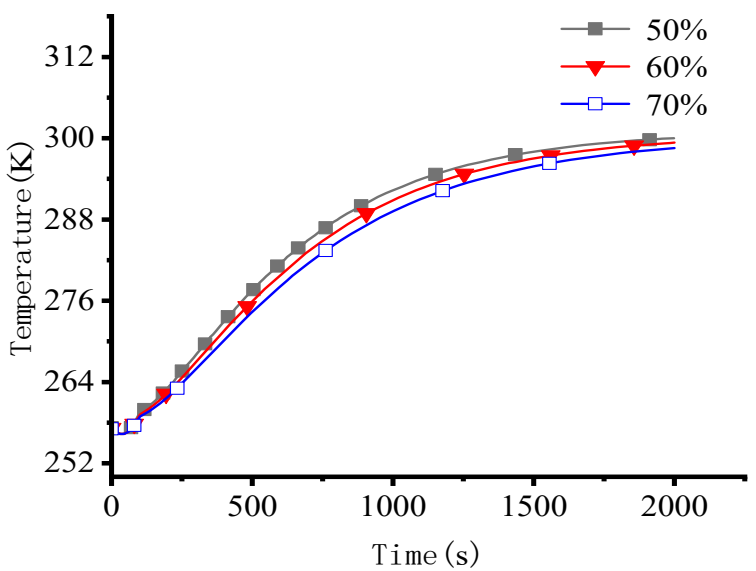

Figure 20. Preheating performance of different concentrations of coolant.

Figure 21 shows the temperature distribution of the battery pack when a mixed solution of different concentrations is used as the preheating liquid. It can be seen that the temperature distribution trend of the battery pack after using the mixed solution of three different concentrations as the preheating liquid is similar. The temperature of the area near the preheating pipe is higher, and the temperature of the central area and the upper surface of the battery part is lower. This is because when the preheating liquid passes through the preheating pipe, the battery part closer to the pipe absorbs more heat. Figure 22 plots the temperature difference in order to better compare the temperature difference among the three schemes.

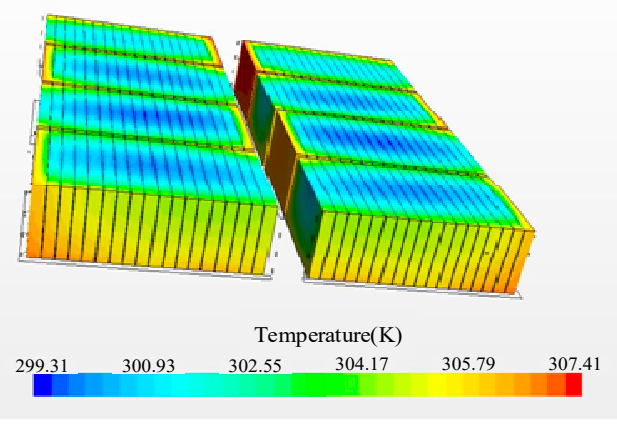

(a) Temperature field of $60 \%$ mixed solution.

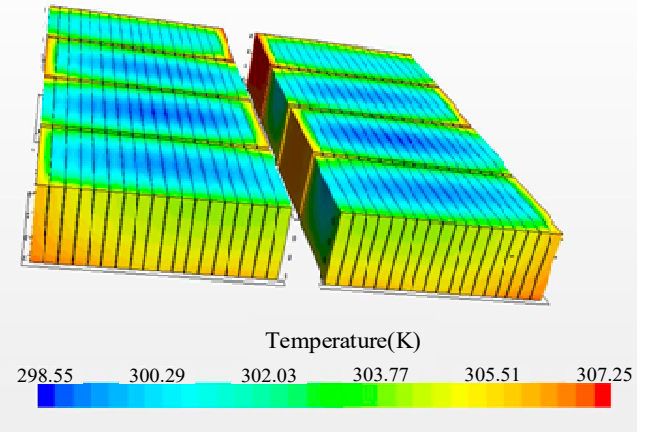

(b) Temperature field of $70 \%$ mixed solution.

Figure 21. Temperature field of battery pack with different concentrations of coolant.

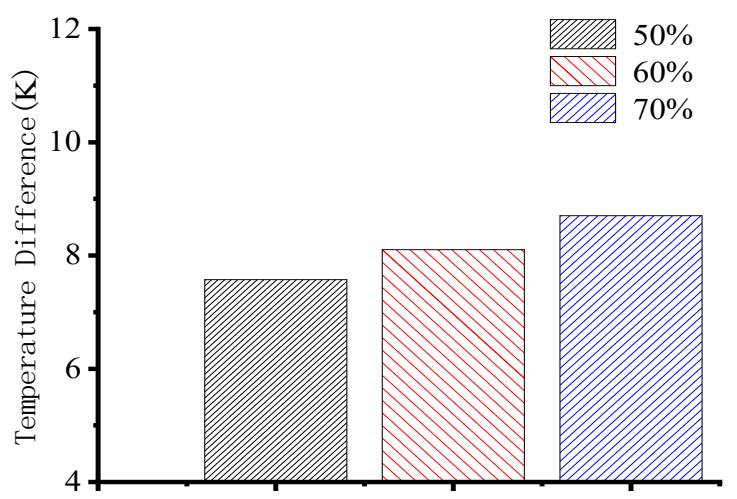

Figure 22. Comparison of the temperature difference in battery pack with different concentrations of coolant. 
It can be clearly seen from the results in Figure 22 that when mixed solutions of different concentrations are used as the preheating solution, the temperature uniformity is slightly different. Among them, the temperature uniformity of the $50 \%$ mixed solution is the best, and the temperature uniformity of the $70 \%$ mixed solution is the worst. However, the difference between the maximum temperature and the minimum temperature of the battery pack and the difference between the maximum temperature and the minimum temperature of the $50 \%$ mixed solution battery pack are not large, and the difference is around $1 \mathrm{~K}$.

\subsection{Different Ambient Temperature Conditions}

Figure 23 shows the temperature of the battery pack after preheating when using a $50 \%$ mixed solution as the preheating solution under different ambient temperatures. It can be seen that when the ambient temperature is $-15^{\circ} \mathrm{C}$, the preheated temperature of the battery pack using the mixed solution of this concentration is approximately $1 \mathrm{~K}$ and $2 \mathrm{~K}$ higher than the preheating temperature of the battery pack when the ambient temperature is $-20^{\circ} \mathrm{C}$ and $-25^{\circ} \mathrm{C}$. When the ambient temperature is $-15^{\circ} \mathrm{C}$, the difference between the maximum temperature and the minimum temperature of the battery pack after preheating is $7.54 \mathrm{~K}$; when the ambient temperature is $-20^{\circ} \mathrm{C}$, this value is $8.332 \mathrm{~K}$; when the ambient temperature is $-25^{\circ} \mathrm{C}$, this value is $9.089 \mathrm{~K}$.

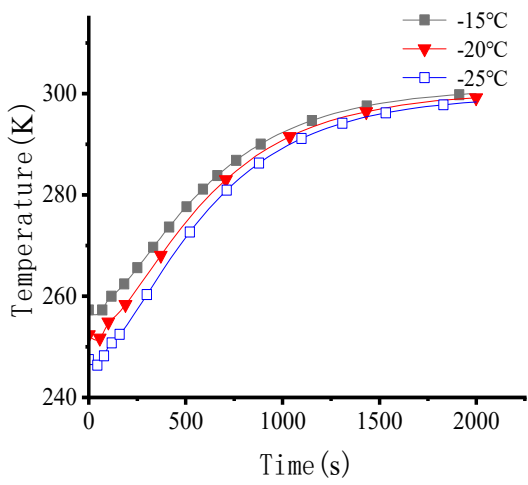

(a) The minimum temperature.

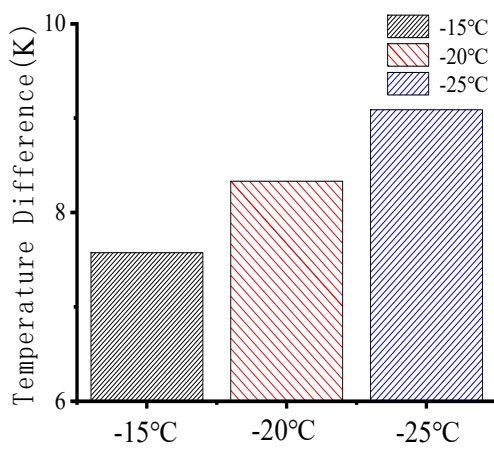

(b) Temperature difference comparison.

Figure 23. Comparison of preheating performance of $50 \%$ solution at different temperatures.

Figure 24 shows the temperature of the battery pack after preheating when $60 \%$ mixed solution is used as the preheating liquid under different ambient temperatures. It can be seen that when the ambient temperature is $-15^{\circ} \mathrm{C}$, the preheated temperature of the battery pack using the mixed solution of this concentration is approximately $1.2 \mathrm{~K}$ and $2.2 \mathrm{~K}$ higher than the preheating temperature of the battery pack when the ambient temperature is $-20^{\circ} \mathrm{C}$ and $-25^{\circ} \mathrm{C}$. When the ambient temperature is $-15^{\circ} \mathrm{C}$, the difference between the maximum temperature and the minimum temperature of the battery pack after preheating is $8.103 \mathrm{~K}$; when the ambient temperature is $-20^{\circ} \mathrm{C}$, this value is $8.913 \mathrm{~K}$; when the ambient temperature is $-25^{\circ} \mathrm{C}$, this value is $9.724 \mathrm{~K}$.

Figure 25 shows the temperature of the battery pack after preheating when $70 \%$ mixed solution is used as the preheating liquid under different ambient temperatures. It can be seen that when the ambient temperature is $-15^{\circ} \mathrm{C}$, the preheated temperature of the battery pack using the mixed solution of this concentration is approximately $1.3 \mathrm{~K}$ and $2.2 \mathrm{~K}$ higher than the preheating temperature of the battery pack when the ambient temperature is $-20^{\circ} \mathrm{C}$ and $-25^{\circ} \mathrm{C}$. When the ambient temperature is $-15^{\circ} \mathrm{C}$, the difference between the maximum temperature and the minimum temperature of the battery pack after preheating is $8.703 \mathrm{~K}$; when the ambient temperature is $-20^{\circ} \mathrm{C}$, this value is $9.573 \mathrm{~K}$; when the ambient temperature is $-25^{\circ} \mathrm{C}$, this value is $10.444 \mathrm{~K}$. 


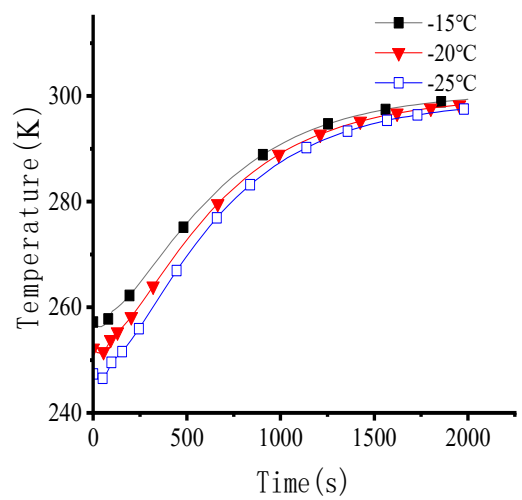

(a) The minimum temperature.

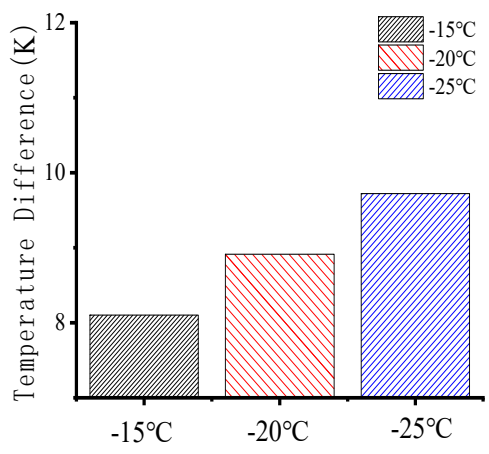

(b) Temperature difference comparison.

Figure 24. Comparison of preheating performance of $60 \%$ solution at different temperatures.

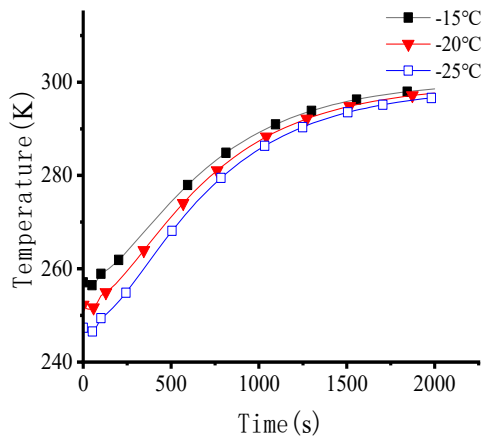

(a) The minimum temperature.

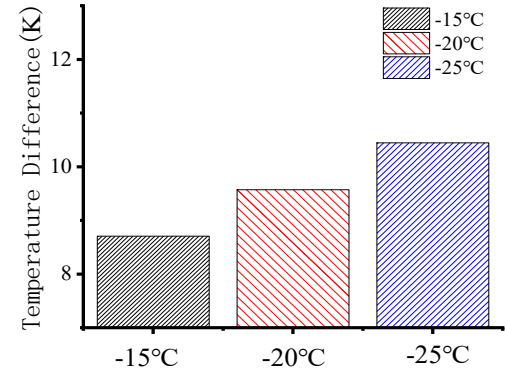

(b) Temperature difference comparison.

Figure 25. Comparison of preheating performance of $70 \%$ solution at different temperatures.

Figures 23-25 show the preheating performance of 50\%,60\% and 70\% mixed solutions, respectively, at different ambient temperatures. It can be seen that for the mixed solutions of these three concentrations, the following laws are met: the lower the ambient temperature, the lower the temperature that the power battery pack can reach after preheating, and the lower the ambient temperature, the worse the temperature uniformity of the power battery pack. In order to better compare the preheating performance, the preheating performance of mixed solutions of different concentrations at different ambient temperatures is presented as a broken line graph in Figures 26 and 27 for comparison.

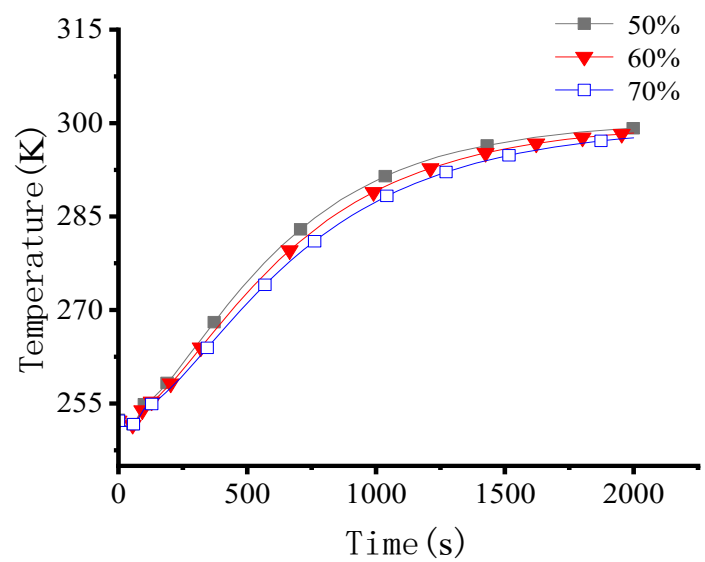

Figure 26. Preheating performance at $-20{ }^{\circ} \mathrm{C}$. 


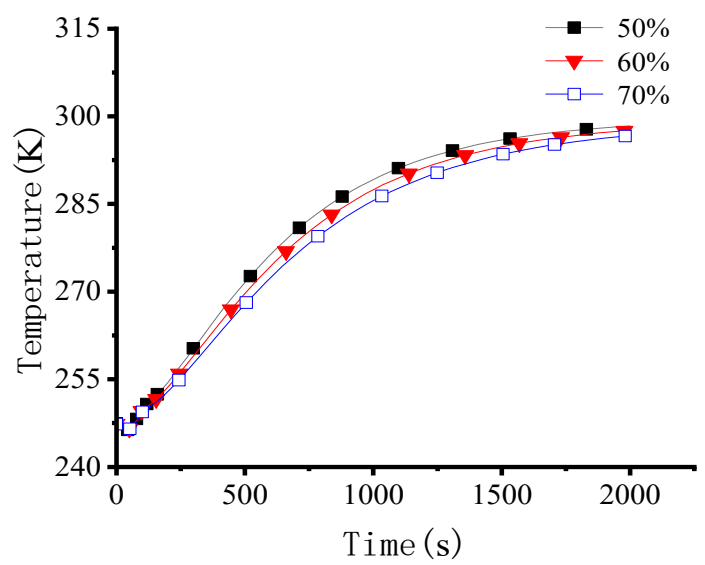

Figure 27. Preheating performance at $-25^{\circ} \mathrm{C}$.

It can be seen from Figure 26 that when the ambient temperature is $-20{ }^{\circ} \mathrm{C}$, the battery pack with $50 \%$ concentration mixed solution as the preheating liquid has the best preheating performance.

Compared with the preheating temperature of the battery pack with $60 \%$ concentration mixed solution and the preheating temperature of the battery pack with $70 \%$ concentration mixed solution, the battery pack using the $50 \%$ concentration mixed solution as the preheating liquid can increase the preheating temperature by around $1.5 \mathrm{~K}$ and $3.5 \mathrm{~K}$, respectively.

It can be seen from Figure 27 that when the ambient temperature is $-25^{\circ} \mathrm{C}$, the $50 \%$ mixed solution has the best preheating performance. Compared with $60 \%$ and $70 \%$ mixed solutions, the preheating temperature can be increased by approximately $1.3 \mathrm{~K}$ and $2.8 \mathrm{~K}$, respectively.

\subsection{Different Preheating Strategies}

The preheating strategy of preheating the power battery pack with a mixed solution at $35^{\circ} \mathrm{C}$ is adopted, and then the power battery pack is discharged for a period of time. In this way, we compare the battery pack's preheating performance at different ambient temperatures. In order to better compare the two preheating strategies, we take a $50 \%$ concentration mixed solution as an example and presented a dotted line graph, shown in Figure 28, for comparison.

It can be seen from Figure 29a that if we only use a preheating method of $50 \%$ mixed solution with a certain temperature flowing through the entire power battery pack when the ambient temperature is $-15^{\circ} \mathrm{C}$ and the power battery pack is preheated with a $50 \%$ mixed solution, it will take around $700 \mathrm{~s}$ to preheat the temperature of the power battery pack to $285 \mathrm{~K}$. Using the above conditions, it takes around $800 \mathrm{~s}$ to preheat the power battery pack to $290 \mathrm{~K}$, and around $1100 \mathrm{~s}$ to preheat the power battery pack to $295 \mathrm{~K}$. However, the $50 \%$ mixed solution with a certain temperature is first used to flow through the entire power battery pack, and then the preheating method of discharging the battery pack takes around $650 \mathrm{~s}$ to preheat to $285 \mathrm{~K}$, around $680 \mathrm{~s}$ to preheat to $290 \mathrm{~K}$ and around $850 \mathrm{~s}$ to preheat to $295 \mathrm{~K}$. By comparison, the second preheating strategy has better preheating performance at an ambient temperature of $-15^{\circ} \mathrm{C}$. When the target temperature is $285 \mathrm{~K}$, it can save approximately $7.1 \%$ of the preheating time. When the target temperature is $290 \mathrm{~K}$, it can save approximately $15 \%$ of the preheating time. Moreover, when the target temperature is $295 \mathrm{~K}$, it can save approximately $22.7 \%$ of the preheating time, which effectively improves the preheating performance.

It can be seen from Figure $28 \mathrm{~b}$ that when the ambient temperature is $-20{ }^{\circ} \mathrm{C}$, the first preheating strategy takes around $730 \mathrm{~s}$ to preheat the power battery pack to $285 \mathrm{~K}$, around $900 \mathrm{~s}$ to preheat to $290 \mathrm{~K}$ and around $1050 \mathrm{~s}$ to preheat to $295 \mathrm{~K}$. However, the time required for the second preheating strategy to preheat to the same target temperature is $700 \mathrm{~s}, 750$ and $870 \mathrm{~s}$, respectively. It can be seen that the second preheating strategy can 
save approximately $4.3 \%$ of the preheating time when the target temperature is $285 \mathrm{~K}$, approximately $16.6 \%$ of the preheating time when the target temperature is $290 \mathrm{~K}$ and approximately $26.7 \%$ of the preheating time when the target temperature is $290 \mathrm{~K}$.

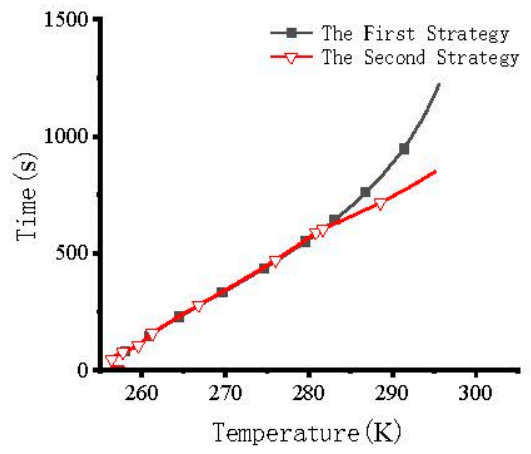

(a)

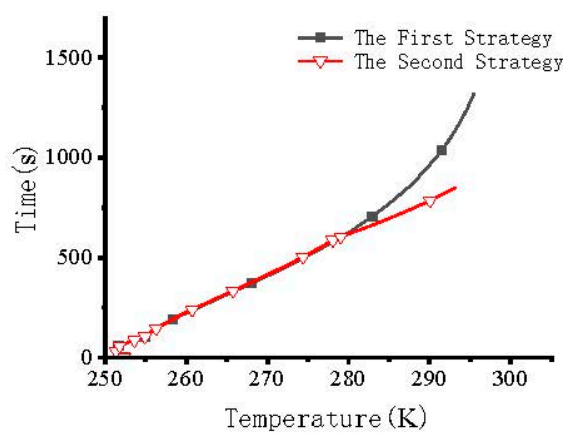

(b)

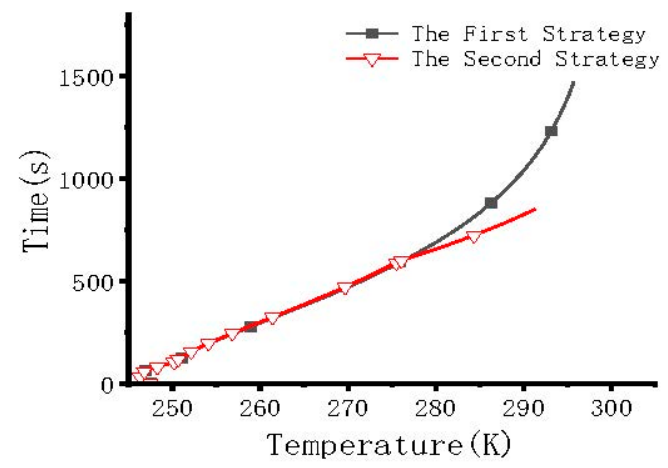

(c)

Figure 28. Preheating performance of two different strategies using 50\% solution at different temperatures. (a) Comparison of the preheating performance of two preheating strategies at $-15{ }^{\circ} \mathrm{C}$ (b) Comparison of the preheating performance of two preheating strategies at $-20^{\circ} \mathrm{C}$. (c) Comparison of the preheating performance of two preheating strategies at $-25^{\circ} \mathrm{C}$.

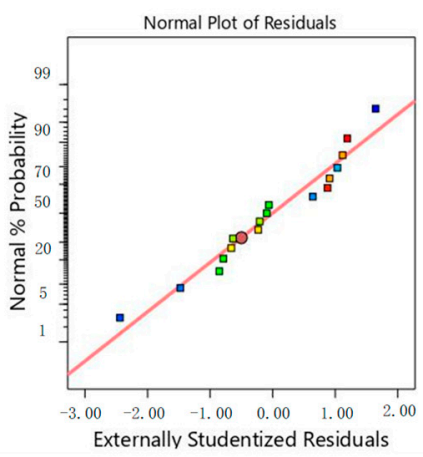

(a)

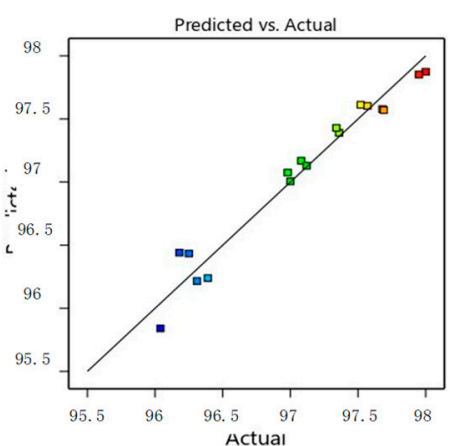

(b)

Figure 29. Schematic diagram of model reliability analysis. (a)The normal probability distribution plot of the residuals. (b) Comparison chart of predicted values and actual test values.

It can be seen from Figure $28 \mathrm{c}$ that when the ambient temperature is $-25{ }^{\circ} \mathrm{C}$, the first preheating strategy takes around $650 \mathrm{~s}$ to preheat the power battery pack to $280 \mathrm{~K}$, around $750 \mathrm{~s}$ to preheat to $285 \mathrm{~K}$ and around $950 \mathrm{~s}$ to preheat to $290 \mathrm{~K}$. However, the time required for the second preheating strategy to preheat to the same target temperature is $600 \mathrm{~s}, 680$ and $800 \mathrm{~s}$, respectively. It can be seen that the second preheating strategy can 
save approximately $7.6 \%$ of the preheating time when the target temperature is $285 \mathrm{~K}$, approximately $9.3 \%$ of the preheating time when the target temperature is $290 \mathrm{~K}$ and approximately $15.8 \%$ of the preheating time when the target temperature is $290 \mathrm{~K}$.

After the above comparison of the two different preheating strategies, the following conclusions can be drawn: when the power battery pack is preheated with a $50 \%$ mixed solution, the battery pack temperature reaches a certain value and then discharges it and continues to be heated to a temperature suitable for work. However, this preheating strategy is less effective than the preheating strategy that only uses the mixed solution for preheating, and the lower the ambient temperature, the longer the preheating time required.

\subsection{Response Surface Optimization}

Response surface optimization is mainly used to investigate the influence of the three factors of the diameter of the preheating pipe, the temperature of the preheating fluid and the thermal conductivity of the material on the temperature field of the power battery pack and obtain the optimal value. The test data for optimization adopt the recorded value of the Star ccm+ simulation result. When using the BBD test method in the Design Expert software, we set the diameter of the preheating pipe, the temperature of the preheating fluid and the thermal conductivity of the material as three independent variables, represented by the letters A, B and C, respectively. The details are shown in Table 5 below.

After determining the independent variables and factor levels of the plan, we then use the temperature equilibrium degree $\mathrm{M}$ of the power battery pack as the dependent variable and enter the value of the dependent variable under different independent variables in the simulation results obtained by Star ccm + into Design Expert. The output results are shown in Table 6 below.

Table 5. Factors of tested independent variables.

\begin{tabular}{|c|c|c|c|c|}
\hline Variable & Code & \multicolumn{3}{|c|}{ Factor Level } \\
\hline $\begin{array}{c}\text { Preheating pipe diameter } \\
\text { value } / \mathrm{mm}\end{array}$ & A & 7.5 & 8 & 8.5 \\
\hline $\begin{array}{l}\text { Preheating liquid } \\
\text { temperature } /{ }^{\circ} \mathrm{C}\end{array}$ & B & 25 & 30 & 35 \\
\hline $\begin{array}{c}\text { Material thermal } \\
\text { conductivity } / \mathrm{W} /(\mathrm{m} \cdot \mathrm{K})\end{array}$ & $\mathrm{C}$ & 4.5 & 5 & \\
\hline
\end{tabular}

Table 6. Factors of tested independent variables.

\begin{tabular}{ccccc}
\hline Test Number & $\begin{array}{c}\text { Diameter of } \\
\text { Preheating Pipe/mm }\end{array}$ & $\begin{array}{c}\text { Preheating Liquid } \\
\text { Temperature/ }{ }^{\circ} \mathbf{C}\end{array}$ & $\begin{array}{c}\text { Thermal } \\
\text { Conductivity/W/(m.K) }\end{array}$ & $\begin{array}{c}\text { Temperature } \\
\text { Balance/M (\%) }\end{array}$ \\
\hline 1 & 7.5 & 25 & 4.5 & 97.68 \\
2 & 8 & 25 & 4.5 & 96.25 \\
3 & 8.5 & 25 & 4.5 & 97.95 \\
4 & 7.5 & 30 & 4.5 & 97.34 \\
5 & 8 & 30 & 4.5 & 96.39 \\
6 & 8.5 & 30 & 4.5 & 97.52 \\
7 & 7.5 & 35 & 4.5 & 96.98 \\
8 & 8 & 35 & 4.5 & 96.04 \\
9 & 8.5 & 35 & 4.5 & 97.08 \\
10 & 7.5 & 25 & 5 & 97.69 \\
11 & 8 & 25 & 5 & 96.18 \\
13 & 8.5 & 25 & 5 & 98.00 \\
14 & 7.5 & 30 & 5 & 97.36 \\
16 & 8 & 30 & 5 & 96.31 \\
\end{tabular}


The regression equation model is as follows:

$$
\begin{gathered}
M=96.23+0.0992 A-0.312 B-0.0119 C-0.045 A B+0.0075 A C- \\
0.0153 B C+1.28 A^{2}-0.0102 B^{2}
\end{gathered}
$$

In Design Expert, the regression Equation (5) is solved for the maximum value. When the diameter of the preheating tube is $8.054 \mathrm{~mm}$, the temperature of the preheating liquid is $32.394{ }^{\circ} \mathrm{C}$, and the thermal conductivity of the material is $4.976 \mathrm{~W} /(\mathrm{m} \cdot \mathrm{K})$. At this time, the predicted value of the temperature equilibrium degree $M$ of the power battery pack is $96.061 \%$, which is the optimal value in these data. This section takes the diameter of the preheating pipe, the temperature of the preheating liquid and the thermal conductivity of the material as the three independent variables, and the regression model variance analysis results with the temperature equilibrium degree $M$ as the dependent variable are shown in Table 7.

Table 7. Variance analysis of regression models.

\begin{tabular}{cccccc}
\hline Factor & $\begin{array}{c}\text { Sum of } \\
\text { Square }\end{array}$ & $\begin{array}{c}\text { Degree of } \\
\text { Freedom }\end{array}$ & $\begin{array}{c}\text { Mean } \\
\text { Square }\end{array}$ & F & $p$ \\
\hline Model & 6.32 & 8 & 0.7904 & 24.43 & $<0.0001$ \\
A-A & 0.1180 & 1 & 0.1180 & 3.65 & 0.0926 \\
B-B & 1.02 & 1 & 1.02 & 31.58 & 0.0005 \\
C-C & 0.0023 & 1 & 0.0023 & 0.0717 & 0.7957 \\
AB & 0.0162 & 1 & 0.0162 & 0.5006 & 0.4993 \\
AC & 0.0007 & 1 & 0.0007 & 0.0209 & 0.8887 \\
BC & 0.0025 & 1 & 0.0025 & 0.0761 & 0.7896 \\
A & 5.52 & 1 & 5.52 & 170.51 & $<0.0001$ \\
$B^{2}$ & 0.0397 & 1 & 0.0397 & & 0.3001 \\
$C^{2}$ & 0.0000 & 0 & 0.0324 & & \\
Residual & 0.2589 & 8 & 16 & & \\
Total error & 6.58 & $\mathrm{R}^{2}=0.9607 \mathrm{R}_{\text {adj }}^{2}=0.9213$ & & \\
\hline
\end{tabular}

It can be seen from Table 7 that the $p$ value of the model is less than 0.0001 , which means that the model is extremely significant. The correlation coefficient $R^{2}$ is 0.9608 , and $\mathrm{R}_{\text {adj }}^{2}$ is 0.9213 . The values of these two coefficients indicate that the regression model designed by the response surface method is effective. The $p$ value of $A^{2}$ is less than 0.001 , indicating that the influence of this factor is extremely significant. It can also be seen that the order of influence of the three single factors on the temperature equilibrium degree $\mathrm{M}$ of the power battery pack is $\mathrm{B}>\mathrm{A}>\mathrm{C}$. Therefore, the influence of the temperature of the preheating liquid is the largest, that of the diameter of the preheating pipe is moderate and that of the thermal conductivity of the material is the smallest.

Figure 29 shows a normal distribution diagram of the residual and a comparison diagram of the residual values and the experimentally predicted values.

\section{Conclusions}

This paper describes the thermal characteristic analysis and simulation discharge analysis of the square lithium iron phosphate battery. The simulation results show that under the same ambient temperature, the greater the discharge rate of the battery, the greater the heat generation, the greater the temperature rise and the more uneven the temperature distribution.

Liquid cooling is adopted to solve the problem wherein air cooling cannot meet the cooling requirements of the battery pack when the battery pack is discharged at a high rate, and the cooling process is simulated. The simulation results show that changing the coolant inlet flow rate can effectively improve the cooling performance of the battery pack under high discharge rate conditions; increasing the number of cooling pipes contained in 
the vertical cooling plate and cooling bottom plate can provide better cooling performance. Changing the order of the inlet and outlet of the coolant can improve the cooling performance. The response surface analysis is performed on the preferred cooling scheme with the best cooling effect, and the best temperature equilibrium is obtained.

A preheating model for a lithium iron phosphate battery is proposed in order to avoid thermal runaway during low-temperature battery charging, and the preheating process is simulated. The simulation results show that a $50 \%$ concentration of water and ethylene glycol mixed solution has the best preheating performance. Adopting the strategy of staged preheating and interspersed discharging can shorten the preheating time of the battery pack, and changing the sequence of the inlet and outlet of the preheating liquid can improve the preheating performance of the battery pack. The response surface analysis method is adopted to optimize the parameters of the preheating model, and the best temperature equilibrium is obtained.

The newly designed heat dissipation structure, cooling scheme and preheating scheme presented in this paper can be used in the new energy vehicle lithium battery heat dissipation structure module to keep the vehicle lithium battery temperature within a safe temperature in order to avoid thermal runaway. However, due to limitations of time and the authors' expertise, this paper still has many shortcomings. Given the current research status of this topic at home and abroad, and the shortcomings of this paper, the authors believe that it can be further researched and improved in the following aspects: the temperature of the battery pack under actual vehicle driving conditions should be considered, such as the discharge of the battery pack and the temperature of the battery pack under various common operating conditions. Moreover, when the calculation conditions allow, the heat dissipation of the overall liquid-cooled battery cooling system and the preheating of the preheating battery pack should be considered, and the module model should be simplified or not simplified as much as possible. The overall structure of the battery pack should be designed. In addition to this, the compressive strength of the geometric structure of the battery pack should also be considered.

Author Contributions: Conceptualization, Y.Z. and S.Z.; Methodology, Y.Z. and S.Z.; Software, Y.Z.; Validation, Y.Z. and S.Z.; Formal Analysis, Y.Z.; Investigation, Y.Z. and S.Z.; Resources, S.Z.; Data Curation, Y.Z.; Writing-Original Draft Preparation, Y.Z. and S.G.; Writing-Review \& Editing, S.G., S.Z. and Y.Z.; Visualization, Y.Z.; Supervision, S.Z.; Project Administration, S.Z.; Funding Acquisition, S.Z. All authors have read and agreed to the published version of the manuscript.

Funding: The research is partially funded by National Key R\&D Program of China (No. 2017YFC0804805).

Institutional Review Board Statement: Not applicable.

Informed Consent Statement: Not applicable.

Data Availability Statement: Not applicable.

Conflicts of Interest: The authors declare no conflict of interest.

\section{References}

1. Rietmann, N.; Hügler, B.; Lieven, T. Forecasting the trajectory of electric vehicle sales and the consequences for worldwide $\mathrm{CO}_{2}$ emissions. J. Clean. Prod. 2020, 261, 121038. [CrossRef]

2. Sun, P.; Bisschop, R.; Niu, H.; Huang, X. A review of battery fires in electric vehicles. Fire Technol. 2020, 56, 1-50. [CrossRef]

3. Börger, A.; Mertens, J.; Wenzl, H. Thermal runaway and thermal runaway propagation in batteries: What do we talk about? J. Energy Storage 2019, 24, 100649. [CrossRef]

4. Pesaran, A.A. Battery thermal models for hybrid vehicle simulations. J. Power Sources 2002, 110, 377-382. [CrossRef]

5. Selman, J.R.; Al Hallaj, S.; Uchida, I.; Hirano, Y. Cooperative research on safety fundamentals of lithium batteries. J. Power Sources 2001, 97, 726-732. [CrossRef]

6. Williford, R.E.; Viswanathan, V.V.; Zhang, J.G. Effect of entropy changes in anodes and cathodes on the thermal behavior of lithium ion batteries. J. Power Sources 2009, 189, 101-107. [CrossRef]

7. Tamura, K.; Horiba, T. Large-scale development of lithium batteries for electric vehicles and electric power storage applications. J. Power Sources 1999, 81, 156-161. [CrossRef] 
8. Weinert, J.X.; Burke, A.F.; Wei, X.Z. Lead-acid and lithium-ion batteries for the Chinese electric bike market and implications on future technology advancement. J. Power Sources 2007, 172, 938-945. [CrossRef]

9. Kitoh, K.; Nemoto, H. 100Wh large size li-ion batteries and safety tests. J. Power Sources 1999, 81, 887-890. [CrossRef]

10. Pesaran, A.A. Battery thermal management in EVs and HEVs: Issues and solutions. Battery Man 2001, 43, 34-49.

11. Rezwan, K.; Maciej, S.; Soren, K.K. Towards an ultimate battery thermal management system: A review. J. Power Sources 2017, 3, 9.

12. Tanim, T.R.; Rahn, C.D.; Wang, C.Y. State of charge estimation of a lithium ion cell based on a temperature dependent and electrolyte enhanced single particle mode. Energy 2015, 80, 731-739. [CrossRef]

13. Wang, Q.; Jiang, B.; Li, B.; Yan, Y. A critical review of thermal management models and solutions of lithium-ion batteries for the development of pure electric vehicles. Renew. Sustain. Energy Rev. 2016, 64, 106-128. [CrossRef]

14. Rao, Z.; Wang, S. A review of power battery thermal energy management. Renew. Sustain. Energy Rev. 2011, 15, 4554-4571. [CrossRef]

15. Zhao, R.; Zhang, S.; Liu, J.; Gu, J. A review of thermal performance improving methods of lithium ion battery: Electrode modification and thermal management system. J. Power Sources 2015, 299, 557-577. [CrossRef]

16. Liang, L.; Zhao, Y.; Diao, Y.; Ren, R.; Jing, H. Inclined U-shaped flat microheat pipe array configuration for cooling and heating lithium-ion battery modules in electric vehicles. Energy 2021, 235, 121433. [CrossRef]

17. Kizilel, R.; Lateef, A.; Sabbah, R.; Farid, M.; Selman, J.; Al-Hallaj, S. Passive control of temperature excursion and uniformity in high-energy Li-ion battery packs at high current and ambient temperature. J. Power Sources 2008, 183, 370-375. [CrossRef]

18. Ling, Z.; Wang, F.; Fang, X.; Gao, X.; Zhang, Z. A hybrid thermal management system for lithium ion batteries combining phase change materials with forced-air cooling. Appl. Energy 2015, 148, 403-409. [CrossRef]

19. Wu, W.; Wang, S.; Wu, W.; Chen, K.; Hong, S.; Lai, Y. A critical review of battery thermal performance and liquid based battery thermal management. Energy Convers. Manag. 2019, 182, 262-281. [CrossRef]

20. Mohammed, M.F.; Selman, J.R. Thermal conductivity enhancement of phase change materials using a graphite matrix. Appl. Therm. Eng. 2005, 26, 1652-1661.

21. Jarrett, A.; KimI, Y. Design optimization of electric vehicle battery cooling plates for thermal performance. J. Power Sources 2011, 196, 10359-10368. [CrossRef]

22. Jarrett, A.; KimI, Y. Influence of operating conditions on the optimum design of electric vehicle battery cooling plates. J. Power Sources 2014, 245, 644-655. [CrossRef]

23. Jin, L.; Lee, P.; Kong, X.; Fan, Y.; Chou, S. Ultra-thin minichannel LCP for EV battery thermal management. Appl. Energy 2014, 113, 1786-1794. [CrossRef]

24. Huo, Y.; Rao, Z.; Liu, X.; Zhao, J. Investigation of power battery thermal management by using mini-channel cold plate. Energy Convers. Manag. 2015, 89, 387-395. [CrossRef]

25. Zhao, J.T.; Rao, Z.H.; Li, Y.M. Thermal performance of mini-channel liquid cooled cylinder based battery thermal management for cylindrical lithium-ion power battery. Energy Convers. Manag. 2015, 103, 157-165. [CrossRef]

26. Panchal, S.; Khasow, R.; Dincer, I.; Agelin-Chaab, M.; Fraser, R.; Fowler, M. Thermal design and simulation of mini-channel cold plate for water cooled large sized prismatic lithium-ion battery. Appl. Therm. Eng. 2017, 122, 80-90. [CrossRef]

27. Rao, Z.; Qian, Z.; Kuang, Y.; Li, Y. Thermal performance of liquid cooling based thermal management system for cylindrical lithium-ion battery module with variable contact surface. Appl. Therm. Eng. 2017, 123, 1514-1522. [CrossRef]

28. Lin, C.J.; Xu, S.C.; Chang, G.F. Experiment and simulation of a LiFePO4 battery pack with a passive thermal management system using composite phase change material and graphite sheets. J. Power Sources 2015, 275, 742-749. [CrossRef]

29. Hallaj, A.S.; Selman, J.R. Novel thermal management system for electric vehicle batteries using phase-change material. J. Electrochem. Soc. 2000, 147, 3231-3236. [CrossRef] 